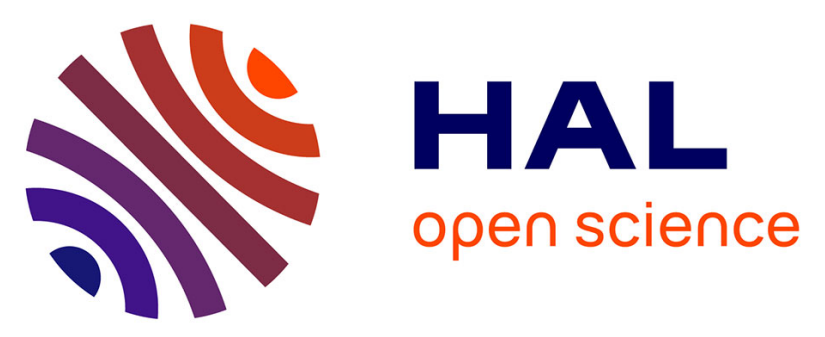

\title{
Design of experiments on the effects of linear and hyperelastic constitutive models and geometric parameters on polymer electrolyte fuel cell mechanical and electrical behaviour
}

Chloé Charbonné, Maria-Lisa Dhuitte, Khadidja Bouziane, Dominique

Chamoret, D. Candusso, Yann Meyer

\section{To cite this version:}

Chloé Charbonné, Maria-Lisa Dhuitte, Khadidja Bouziane, Dominique Chamoret, D. Candusso, et al.. Design of experiments on the effects of linear and hyperelastic constitutive models and geometric parameters on polymer electrolyte fuel cell mechanical and electrical behaviour. International Journal of Hydrogen Energy, 2021, 46 (26), pp.13775-13790. 10.1016/j.ijhydene.2021.02.122 . hal-03188311

\author{
HAL Id: hal-03188311 \\ https://hal.science/hal-03188311
}

Submitted on 8 Apr 2021

HAL is a multi-disciplinary open access archive for the deposit and dissemination of scientific research documents, whether they are published or not. The documents may come from teaching and research institutions in France or abroad, or from public or private research centers.
L'archive ouverte pluridisciplinaire HAL, est destinée au dépôt et à la diffusion de documents scientifiques de niveau recherche, publiés ou non, émanant des établissements d'enseignement et de recherche français ou étrangers, des laboratoires publics ou privés. 


\title{
DESIGN OF EXPERIMENTS ON THE EFFECTS OF LINEAR AND HYPERELASTIC CONSTITUTIVE MODELS AND GEOMETRIC PARAMETERS ON POLYMER ELECTROLYTE FUEL CELL MECHANICAL AND ELECTRICAL BEHAVIOUR
}

\author{
C. Charbonné ${ }^{1}$, M.-L. Dhuitte ${ }^{1}$, K. Bouziane ${ }^{1,2,3,4}$, D. Chamoret $^{5}$, D. Candusso ${ }^{2,4}$, and Y. \\ Meyer $^{3,6}$ \\ ${ }^{1}$ Université Bourgogne Franche-Comté, UTBM, 90010 Belfort Cedex, France. \\ ${ }^{2}$ Université Paris-Saclay, Université Gustave Eiffel, SATIE (Systèmes et Applications des \\ Technologies de l'Information et de l'Energie), 25 allée des marronniers, 78000 Versailles \\ Satory, France. \\ 3 Université de technologie de Compiègne, CNRS, Roberval (Mechanics Energy and \\ electricity), Centre de recherche Royallieu - CS 60319 - 60203 Compiègne Cedex, France. \\ ${ }^{4}$ FCLAB, Plateforme Hydrogène Energie, UTBM bât. F, Rue Thierry Mieg, 90010 Belfort \\ Cedex, France. \\ ${ }^{5}$ ICB UMR 6303, CNRS Univ. Bourgogne Franche-Comté, UTBM, Belfort, France. \\ ${ }^{6}$ Laboratoire SYMME, Université Savoie Mont Blanc, Annecy-le-Vieux, France.
}

[*] Corresponding author's email: charbonne.chloe@gmail.com; maria-lisa.dhuitte@utbm.fr Other emails: khadidja.bouziane@utbm.fr, dominique.chamoret@utbm.fr, yann.meyer@univ-smb.fr,denis.candusso@univ-eiffel.fr.

"Declaration of interest: None." 


\section{Abstract:}

In this work, the influence of the geometric and mechanical properties of the constitutive layers of a Proton Exchange Membrane Fuel Cell (PEMFC) on the system performance was investigated. More specifically, this study focused on the internal electrical resistances due to the interlayer mechanical contacts. Indeed, electrical contact resistances are one of the main sources of ohmic losses in a PEMFC and therefore require special attention to improve the system efficiency. To this end, a Design of Experiments associated with a 2D Finite Element Model including contact friction was developed and used. The typology (linear or hyperelastic) of the constitutive law of a Gas Diffusion Layer (GDL) and the layer thicknesses were parametrized and investigated. The analysis of the results shows that the impact of thicknesses and thickness ratios on PEMFC performance is more important than the typology of the GDL constitutive law.

\section{Keywords:}

Fuel cell, Mechanical contact pressure, Electrical contact resistance, Design of Experiments, Non-linear and Linear behaviour.

\section{Highlights:}

- A 2D finite element model of a single fuel cell with contact friction is developed.

- A hyperelastic experimental constitutive law of the GDL used is implemented.

- Optimal set of geometric and mechanical parameters is determined with a DoE.

- The ratios between the component thicknesses influence the computation stability.

- Performances are more impacted by layer thicknesses than by GDL constitutive law. 


\begin{tabular}{llll}
\hline Symbols & Description & $\begin{array}{l}\text { Superscripts } \\
\text { and } \\
\text { subscripts }\end{array}$ & Description \\
\hline $\mathrm{a}$ & $\begin{array}{l}\text { Contact width (x direction } \\
\text { see Fig.1 \& Table 2) }\end{array}$ & 2D/3D & Two Dimensions/ Three Dimensions \\
$\mathrm{b}$ & $\begin{array}{l}\text { Contact height (z direction } \\
\text { see Fig.1 \& Table 2) }\end{array}$ & $\mathrm{BPP}$ & BiPolar Plate \\
$\mathrm{E}$ & Young Modulus & $\mathrm{CP}_{\text {RESS }}$ & Contact Pressure \\
$\mu$ & $\begin{array}{l}\text { Coefficient of adhesion } \\
\text { friction }\end{array}$ & $\mathrm{CR}$ & Electrical Contact Resistance \\
$\mathrm{N}$ & Normal Plan force & DoE & Design of Experiment \\
$\mathrm{T}$ & Tangential force & GDL & Gas Diffusion Layer \\
$\mathrm{u}_{1}$ & X direction & FC & Fuel Cell \\
$\mathrm{u}_{2}$ & Y direction & FE & Finite Element \\
$\mathrm{s}$ & seconds & FEM & Finite Element Method \\
$\varepsilon$ & Logarithmic strain (or true & MEA & Membrane Electrode Assembly \\
$v$ & strain) & MPa & Mega Pascal \\
$\varphi$ & Poisson's ratio & PEMFC & $\begin{array}{l}\text { Polymer Electrolyte Membrane Fuel Cell } \\
\text { (also called Proton Exchange Membrane }\end{array}$ \\
& Grip angle & & Fuel Cell) \\
\hline
\end{tabular}

\section{Introduction}

Proton Exchange Membrane Fuel Cells known for their high efficiency [1] - quick start at room temperature, and the variety of applications (stationary systems, mobile devices, transportation [2] and space applications [3]) is a promising substitute for combustion engines owing to its low level of output pollutants. Great efforts have been done toward the commercialization of PEMFC in energy market but a larger deployment involves enhancing their efficiency, lifetime $[4,5,6]$, reducing their costs and improving electrical power production. The link between the energetic performance of a PEMFC and external-internal mechanical excitations [7] , as well as environmental conditions is one of the significant factors influencing its industrialization [8].

The literature on these mechanical aspects and the selection criteria of cell components are relatively limited [9]. To enhance these systems, it is thus necessary to have preliminary design models meeting the requirements of reliability and performance, reducing PEMFC cost and increasing lifespan. A preliminary design model is developed to allow the initial exploration of the design space with a limited computation cost. The early-stage design is important because the major design choices are made at this stage, in particular the product architecture. For 
example, this could enable to design new stack compression systems for assembly procedures and FC operation by reducing Ohmic losses in the electrical power generator. After this stage, the potentialities for product innovation or modification are quite limited [10]. Consequently, from the beginning of the design process, it is important to have a better understanding of the parameters that play a role in electrical power generation, such as the electrical Contact Resistance (CR) which influences the electronic losses.

Among the external excitations of a PEMFC, there are assembly procedures, operational and environmental aggressive conditions. Here, we will be interested in the mechanical clamping of stack [11] which is used in order to assemble different components of PEMFC. This mechanical stress influences the global FC performance $[12,13,14]$. To optimize the performance of a PEMFC, the mechanical excitations must be handled. The mechanical compression during mechanical clamping reduces Ohmic losses due to the resistance of the GDLs and rise of mass transport losses by reducing the porosity of the GDL.

Among the components of PEMFC, GDLs play a major role in the cell performances by allowing a homogeneous distribution of gas from the channels to the membrane. In fact, most papers treating PEMFC analysis and modelling use a linear GDL constitutive law. Articles focusing on GDLs sometimes consider a hyperelastic constitutive law [15]. However, to the knowledge of the authors, the comparison between these linear and hyperelastic behaviours is little explored. The experimental study described in [8] point out that "contact resistance was found to decrease non-linearly with compression: more than $75 \%$ of reduction was attained at 2.5 MPa". The representativeness of the preliminary models involves the study of nonlinearities, in particular for GDL [16]. In this paper, we are especially interested in the influence of the GDLs constitutive law (linear and hyperelastic constitutive laws) and the layer thicknesses on the contact pressure (CPRESS) on the performance of PEMFC. Geometry, especially all the layer thicknesses, plays an important role in the performance of PEMFC. The layer thicknesses influence the variation of the mechanical stresses and therefore affects performance. The PEMFC performance is associated with contact pressure CPress as in Eq. (1).

CPress $=\frac{N}{a \times b}$

With

- N: Normal plan force [Newton],

- $\quad \mathrm{a} \times \mathrm{b}$ : the real contact surface between interface $\left[\mathrm{m}^{2}\right]$. 
The performance in terms of power generating depends of protonic losses and Ohmic losses. About $50 \%$ of electronic losses stem from Contact Resistance (CR) $[17,18]$. At each interface, there will be a loss of current intensity due to insufficient surface-to-surface contact. Studies have found that Mechanical CPress can strongly affect CR [11,12] and a relation between CR and CPress was observed $[13,19]$. The most important electronic ohmic losses in FC are at the BPP - GDL interface with the electrical CR [7,20]. The aim is therefore to have the optimal contact pressure in order to reduce the $\mathrm{CR}$ as much as possible $[21,22]$.

The paper goes further by using a Design of Experiments (DoE) with a 2D Finite Element (FE) Model including contact friction to study the effect of geometry and constitutive law of materials, on the mechanical and electrical performance of a PEMFC stack. To validate and assess numerical results, we will make comparisons with experimental results from literature. Our methodology is presented in the next section. The results of the parameters effects on the overall performance are shown in Section 3. The last section is a critical discussion of our study.

\section{Methods}

The main purpose of this study is to investigate the effects of geometry and GDL constitutive law on CPress. A 2D Finite Element (FE) model with contact friction has been developed to simulate the mechanical properties to obtain CPress and von Mises yield criterion. An effective approach is proposed to save CPU time with DoE methods, by using Taguchi approach. DoE provides also an optimal simplified model to maximize the pressures for each interface and minimize the constraints.

\subsection{Finite Element Method}

A FE model has been developed with the commercial software ABAQUS [23]. This software uses the Finite Element Method (FEM) to solve engineering and mechanical problems. The FE Modelling permits to build a representation of a problem in a model and to give the structure behaviour subjected to environmental conditions and to external / internal mechanical excitations. 


\subsubsection{Geometry and Model}

A 2D axisymmetric plane strain FE model has been modelled on ABAQUS. This modeling is aimed to obtain a global mechanical behaviour and not a local one. In order to limit the computation (CPU) time, the model is simplified without BPP distribution channels. The elastomeric gaskets are not included in the model. This assumption is based on the fact that the force on the gasket used only represents $5 \%$ of the total clamping force [24]. In order to have an efficient and effective model, a single fuel cell was simulated. Due to symmetry of a cell, we had only modelled half of the single fuel cell. These assumptions allow reduced computation times. The model components are EP (End Plate), BPP, GDL, and MEA as shown in Figure. 1.

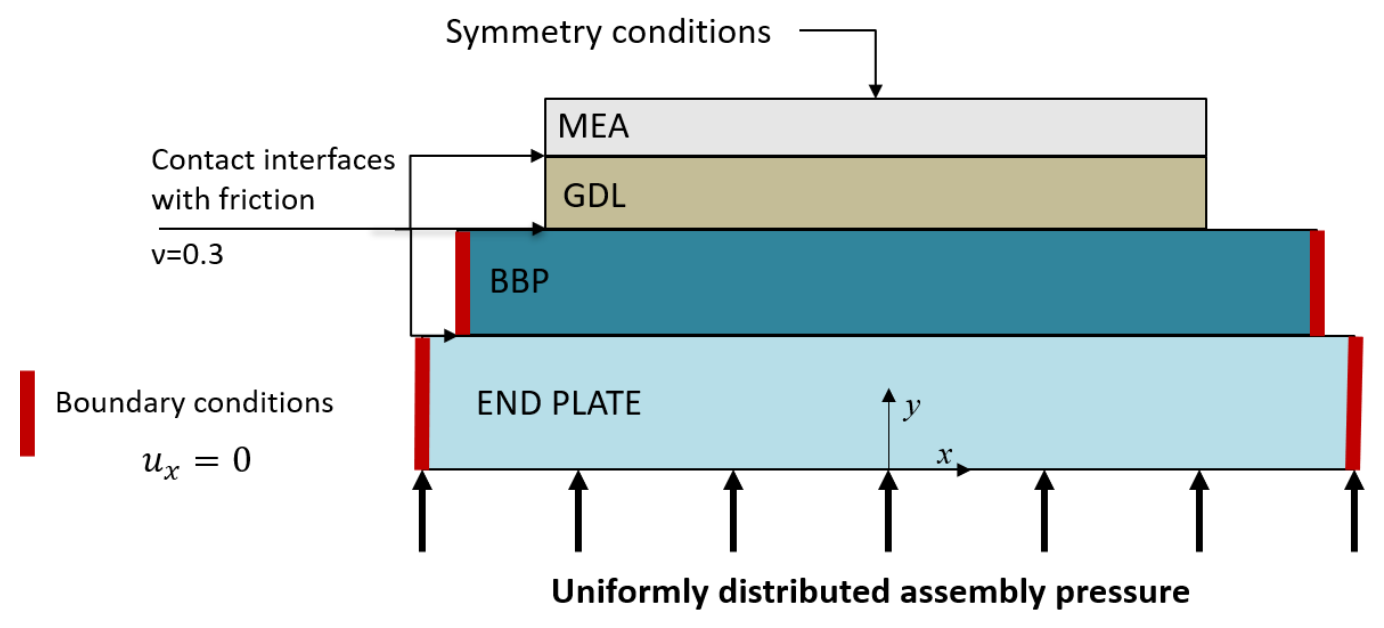

Figure 1: Model of a single fuel cell

The point of view adopted in this paper is the development of a preliminary model. The modeling assumptions result from this choice. The FE model is built with the following assumptions:

Assembly pressure of $1 \mathrm{MPa}$ applied uniformly on the collector plate.

Boundary condition applied on BPP and EP is $\mathrm{u}_{1}=0$ (see Figure 1).

Symmetry condition applied on MEA.

- Coefficient of adhesion friction is $\mu=0.3$, Coulomb's law $T=N . \mu=N \cdot \tan \varphi$ [24].

The widths and the heights in direction $\mathrm{x}$ and $\mathrm{z}$ are constant as presented in Figure 1 and Table 1 ; the thicknesses in y direction are variants. Our first objective is to quantify the impact of thicknesses on CPress and so on CR. Our second purpose is to observe the consequence of the GDL constitutive law on the mechanical and electrical behaviour of a PEMFC. For this purpose, 
the model developed by Mishra [25] is applied to link mechanical contact pressure and electric contact resistance (and thus the PEMFC performance). Thus, it is possible to take into account analytically the geometry of the BPP and limit the loss of accuracy. A balance between computation time and accuracy was sought.

Table 1: Description of the model geometry

\begin{tabular}{|c|c|c|}
\hline & Width [mm] & Height [mm] \\
\hline EP & 350 & 350 \\
\hline BPP & 295 & 295 \\
\hline GDL & 200 & 200 \\
\hline MEA & 200 & 200 \\
\hline
\end{tabular}

\subsubsection{Material properties}

The mechanical behaviour is included in the assembly model with homogeneous and isotropic materials. The constitutive laws applied derive from mechanical stress-strain tests. Gigos et al. found that the GDL behaviour is linear for small deformations but non-linear in large deformations [26]. Better still, the irreversible and non-linear nature of the hysteresis cycle depend on the number of loading-unloading cycles with a stabilization after 5 cycles. Note that the study focuses on the influence of GDL constitutive law on contact pressure with hyperelastic and linear constitutive law. The elastic material properties of EP, BPP, GDL, and MEA are listed in Table 2. The mechanical properties of the Nafion membranes (112,115 and 211) are given for $90 \% \mathrm{RH}$ at $40{ }^{\circ} \mathrm{C}$ [27]. For simplicity, this hydration level is assumed to be constant throughout the compression process, although in real applications this may not be necessarily true. The GDL hyperelastic constitutive law was extracted from uniaxial experimental data with a Marlow deformation energy potential model [26].

Table 2: Mechanical properties of the PEMFC components

\begin{tabular}{|c|c|c|c|}
\hline Cell component & Material & Young modulus [MPa] & Poisson's ratio \\
\hline EP & Aluminium alloy & 70000 & 0.33 \\
\hline BPP & Graphite & 5100 & 0.25 \\
\hline GDL & TGP-H-90 & 60 & 0.25 \\
\hline
\end{tabular}




\begin{tabular}{|l|l|l|l|}
\hline MEA & Nafion & 190 & 0.25 \\
\hline
\end{tabular}

The GDL has a hyperelastic behaviour due to its microscopic structure. Therefore, using a linear constitutive law is an assumption to be carefully used. As shown in Figure 2, for a GDL deformation smaller than $\varepsilon=0.14$, the linear nominal stress will be lower (up to $56.12 \% \max$ ) than Marlow's stress (non-linear). And near to zero and for $\varepsilon=0.14$, the differences between these laws are slight.

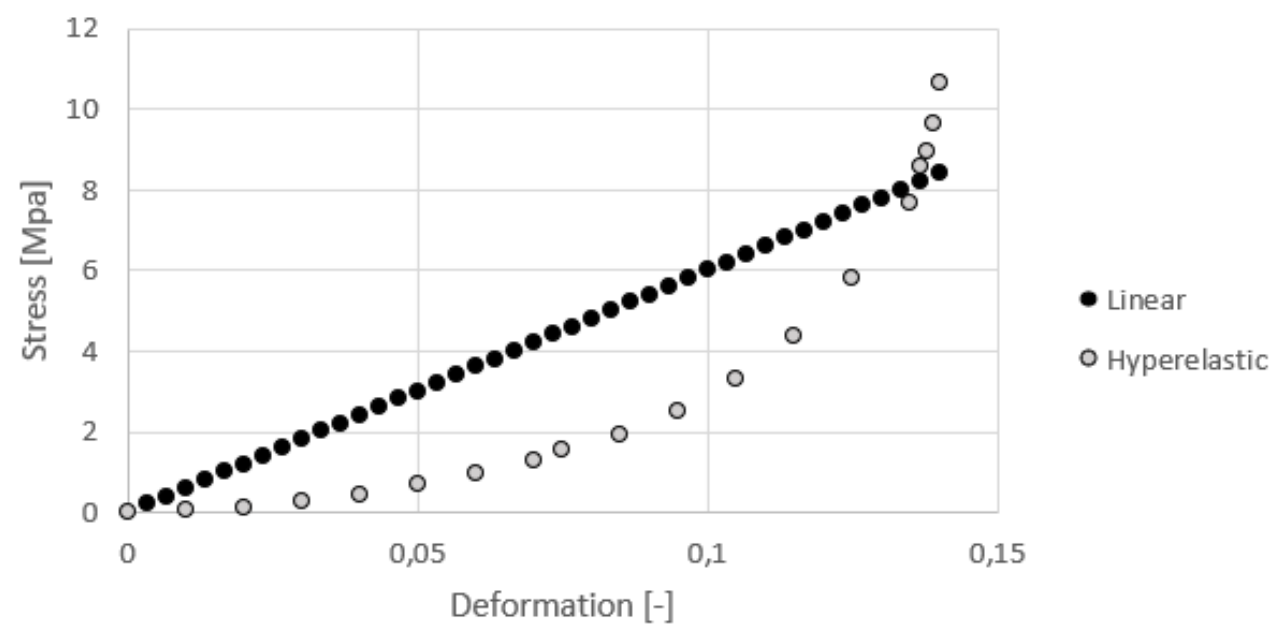

Figure 2: Relation stress/strain of GDL - comparison between linear/hyperelastic laws

\subsubsection{Meshing}

In this FE modelling, the greatest difficulty is to keep a continuity in the mesh with a great variation in thickness. The MEA can be five hundred times smaller than BPP. The mesh has element shape quad dominated with CPE4RH element type a 4-node bilinear plane strain quadrilateral in linear interpolation [23]. The node and element numbers of the half-single fuel cell are given in Table 3 .

Table 3: Mesh description

\begin{tabular}{|c|c|c|}
\hline Test & Node numbers & Element numbers \\
\hline 1 & 142294 & 121976 \\
\hline 2 & 181601 & 161284 \\
\hline 3 & 11602 & 8735 \\
\hline
\end{tabular}




\begin{tabular}{|c|c|c|}
\hline 4 & 25655 & 19484 \\
\hline 5 & 222898 & 202568 \\
\hline 6 & 147107 & 133750 \\
\hline 7 & 30987 & 26000 \\
\hline 8 & 35000 & 39013 \\
\hline 9 & - & - \\
\hline
\end{tabular}

The FE number is investigated to have a good mesh quality on the entirety of the model. The aim is to have a sufficiently fine mesh so that the results are consistent and the CPU time short. Hence the size mesh of the model is adapted in function of the variations in thickness as shown in Figure 3. To guarantee the quality of the results, we have chosen at least two elements in the thickness of each component. The compromise for the overall mesh size is between 0.01 and 2.5 depending on thickness size.

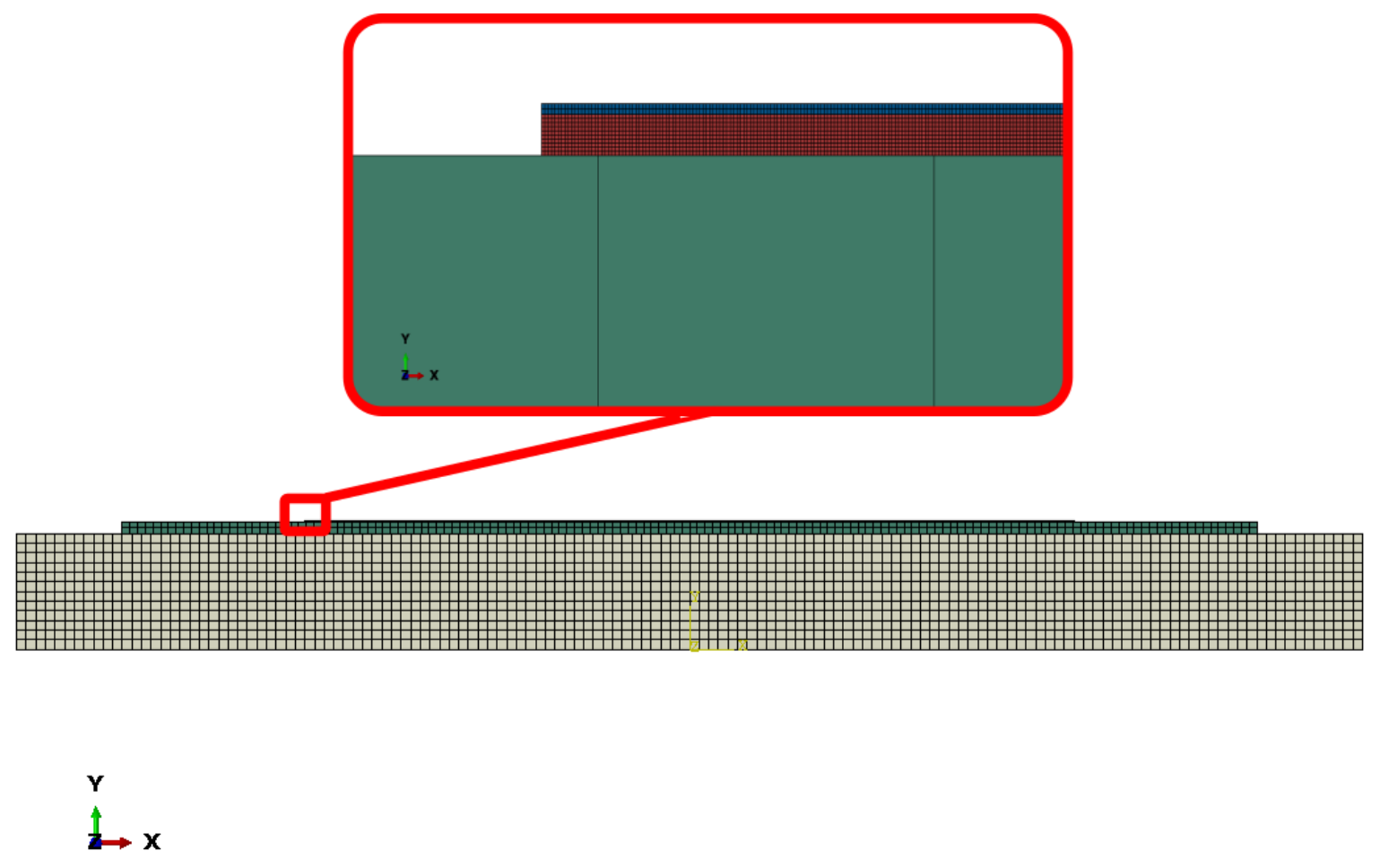

Figure 3: Mesh used for computations 


\subsubsection{Parameterization of Abaqus}

To set up our models, two steps are created to simulate an assembly procedure. One initial step at 0 "time" period and another one at 1 "time" period. In a nonlinear analysis, a step takes place over a finite period of "time", although this "time" has no physical meaning unless inertial effects or rate-dependent behaviour are important. The incrementation is automatic with a maximum number of 100 increments. The initial increment size is between 0.0001 and 0.01 . The maximum increment size is 1 and the minimum lies between $1 \mathrm{E}-30$ and $1 \mathrm{E}-05$. The other step parameters are the selection of the direct solver method and the full Newton solution technique. A linear extrapolation, in "time", of the previous incremental solution is used to begin with the non-linear equation solution for the current increment. The uniform pressure is $0 \mathrm{MPa}$ at initial step and loaded of $1 \mathrm{MPa}$ at charge step. The boundary conditions are applied on BPP and EP. The BPP and EP have the boundary condition $\mathrm{u}_{1}$ blocked and a symmetry on the MEA with $\mathrm{u}_{2}=0$ as seen in Figure 1 . The representations used in Abaqus for the interactions between components are: surface-to-surface contact (standard) type with master surface and slave surface. The contact interaction property is a tangential behaviour isotropic and friction coefficient about 0.3. To avoid interpenetration between each element, a non-penetration constraint is applied. The analysis is run in Abaqus/Standard with the Newton-Raphson method on 4 processors and 1 GPGPU acceleration. To ensure the convergence of the calculations, the initial increment size could be decreased.

\subsection{Design of Experiments with Taguchi approach}

\subsubsection{Explanation for simplification}

A DoE is a useful tool for designing a product or solving complex optimization systems. It allows saving time thanks to a series of tests organized in advance to understand and quantify multiple parameters in a minimum of tests. It avoids combining all the modalities of all the parameters. Using a DoE table, the number of tests is given in Equation (2).

model number $=$ LEVEL $L^{\text {factor }}$

With:

Factor: number of parameters to vary; factors are independent variables,

Level: numbers of factor values. 
The Taguchi approach permits to reduce model number thanks to standard tables which list the most common combinations of levels and factors [28].

\subsubsection{Modalities}

The model has 4 factors: thicknesses of EP, GDL, BPP, and MEA. We chose to work with levels equal to 3 . To highlight the influence of geometry with a classical DoE method, we would have had $3^{4}$ run, so 81 different models to run. Moreover, as we also studied the influence of the constitutive law on the contact pressure, we would have two tables of DoE: one table with GDL hyperelastic constitutive law and the other one with GDL linear constitutive law. Consequently, 162 models should have run.

For 4 factors with 3 levels, the table for the Taguchi approach is an experimental matrix L9 with 9 the model number. Tables 4 and 5 respectively give the description of models and the details of the different factors and levels. The Taguchi method allows reducing the number of models from 162 to 18 .

Table 4: Description of models in the Taguchi approach

\begin{tabular}{|c|c|c|c|c|c|}
\hline Test Nr. & \multicolumn{4}{|c|}{ Levels of controlled factors } & Results \\
\hline & A & B & C & D & \\
\hline 1 & 1 & 1 & 1 & 1 & R1 \\
\hline 2 & 1 & 2 & 2 & 2 & R2 \\
\hline 3 & 1 & 3 & 3 & 3 & R3 \\
\hline 4 & 2 & 1 & 2 & 3 & R4 \\
\hline 5 & 2 & 2 & 3 & 1 & R5 \\
\hline 6 & 2 & 3 & 1 & 2 & R6 \\
\hline 7 & 3 & 1 & 3 & 2 & R7 \\
\hline 8 & 3 & 2 & 1 & 3 & R8 \\
\hline 9 & 3 & 3 & 2 & 1 & R9 \\
\hline
\end{tabular}

Table 5: Description of the levels (thicknesses) in the DoE 


\begin{tabular}{|c|c|c|c|}
\hline \multirow{2}{*}{ Factors } & Level 1 & Level 2 & Level 3 \\
\hline \multirow{2}{*}{ A - MEA } & Nafion-112 & Nafion-115 & NR 211 \\
\cline { 2 - 4 } & 0.05 & 0.127 & 0.0254 \\
\hline \multirow{2}{*}{ B - GDL } & TGP-H-060 & TGP-H-090 & TGP-H-120 \\
\cline { 2 - 4 } & 0.19 & 0.28 & 0.37 \\
\hline \multirow{2}{*}{ C - BPP } & 3 & 6.35 & 12.7 \\
\cline { 2 - 4 } & 30 & 15 & 7.5 \\
\hline \multirow{2}{*}{ D - EP } & 3 Bipolar Graphite Plate \\
\hline
\end{tabular}

\subsection{Coupling FEM and DoE}

As presented in Subsection 2, in a first step, the geometry and material characteristics are chosen in the literature dedicated to PEMFCs $[29,30,31,32]$. In a second step, the mechanical properties given in subsections 2.1 and 2.2 are simulated with the software ABAQUS [23]. Finally, as explained in Subsection 2.2, the DoE factors are extracted following the flowchart in Figure 4. This methodology implied to simulate a configuration of mechanical properties individually. 9 tests have been modelized. For every model, CPress and the von Mises yield criterion are extracted for each step of increment. All the curves presented in this paper are related with the loading step at $1 \mathrm{~s}$.

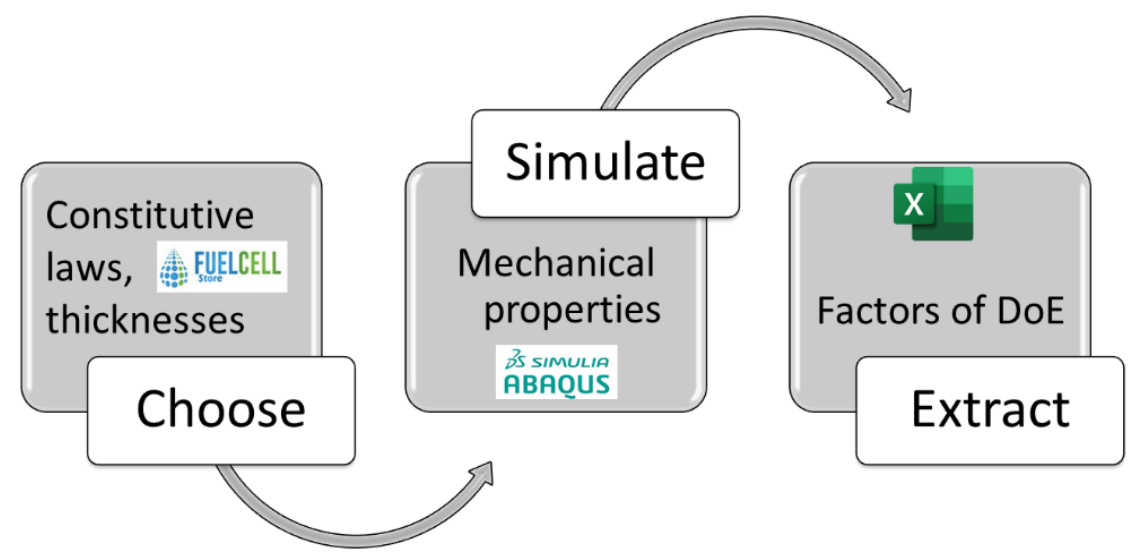

Figure 4: Methodology for coupling FEM and DoE 


\section{Results}

The mechanical behaviours of the PEMFC components are described in the following section, which also includes a detailed comparison between our numerical results and those from the literature.

\subsection{Geometry effects and most influential components}

\subsubsection{Geometry effects on the model convergence}

Concerning the choice of the factor D-EP to level 3 (D3) in the selected Taguchi table, a first set of simulations with a value of $1.588 \mathrm{~mm}$ was achieved. Tests $3,4,8$, and 9 could not converge. In the analysis of the inconclusive tests, we observed that there could not be a smaller End Plate (EP) than the BPP. On the one hand, with a BPP thickness below than $10 \%$ of the EP thickness, the numerical calculations did not run. We assume that is due to a significant penetration of the materials with each other. Thanks to a new value of 7.5 selected for D3, we were able to run Tests 3, 4, and 8. On the other hand, regarding Test 9, we concluded that a very thin MEA in front of the GDL and/or EP has a negative impact on the convergence of the calculation. Indeed, in Test 9, the MEA-GDL thickness ratio (7\%), and especially the MEA-EP thickness ratio $(0.08 \%)$, are smaller compared to the thickness ratios of the other tests. There are no results for the Tests 9 because their thickness ratios have remained disadvantageous for the calculation in Table 6. By analyzing the inconclusive tests, it is possible to establish preliminary design rules for the numerical model (and maybe the physical stack) based on thickness ratios: the MEA/GDL ratio must be greater than 9\%, the MEA/EP ratio between $0.7 \%$ and $1.7 \%$, the GDL/EP ratio less than $12 \%$ and the BPP/EP ratio less than 190\%. A detailed study on the thickness ratios effects on the numerical model would surely be very interesting.

Table 6: Maximum pressure and von Mises yield criterion for hyperelastic GDL

\begin{tabular}{|c|c|c|c|c|c|c|}
\hline \multicolumn{1}{|c|}{ Hyperelastic GDL } \\
\hline \multirow{3}{*}{ Results } & \multicolumn{2}{|c|}{ Mex. von Mises yield criterion [MPa] } & \multicolumn{3}{c|}{ Max. contact pressure [MPa] } \\
\cline { 2 - 7 } & $\begin{array}{c}\text { Contact GDL- } \\
\text { MEA }\end{array}$ & $\begin{array}{c}\text { Contact BPP- } \\
\text { GDL }\end{array}$ & $\begin{array}{c}\text { Contact EP- } \\
\text { BPP }\end{array}$ & $\begin{array}{c}\text { Contact GDL- } \\
\text { MEA }\end{array}$ & $\begin{array}{c}\text { Contact BPP- } \\
\text { GDL }\end{array}$ & $\begin{array}{c}\text { Contact EP- } \\
\text { BPP }\end{array}$ \\
\hline R1 & 7.81 & 2.75 & 7.27 & 8.2 & 8.2 & 7.62 \\
\hline R2 & 14.37 & 5.87 & 2.29 & 14.45 & 14.27 & 9.75 \\
\hline
\end{tabular}




\begin{tabular}{|c|c|c|c|c|c|c|}
\hline R3 & 23.57 & 15.56 & 16.15 & 23.84 & 31.61 & 8.58 \\
\hline R4 & 30.84 & 34.34 & 107.85 & 34.66 & 62.51 & 15.49 \\
\hline R5 & 14.37 & 2.75 & 7.27 & 8.05 & 8.04 & 7.62 \\
\hline R6 & 13.86 & 5.95 & 14.5 & 15.52 & 15.34 & 13.29 \\
\hline R7 & 13.98 & 13.83 & 7.98 & 13.18 & 5.6 & 8.66 \\
\hline R8 & 42.93 & 48.45 & 30.4 & 41.13 & 115.2 & 22.25 \\
\hline R9 & - & - & - & - & - & - \\
\hline
\end{tabular}

\subsubsection{Geometric effects on the mechanical behaviour}

First, let us note that we aim to minimize the von Mises yield criterion in order to limit the load on the components and thus avoid the definitive failure of the materials. On the other hand, the contact pressure at the interfaces needs to be maximized since the more surface will be in contact, the better the contact resistance and therefore the FC performance.

Table 6 shows the maximum von Mises yield criterion and the maximum contact pressures at the interfaces of our models with a hyperelastic constitutive law for the GDL. The remarkable values come from Tests 2 and 8 . In Test 2, the smallest von Mises yield criterion is between the EP and the BPP: 2.29 MPa. In Test 8, the highest stress pressure is between the BPP and the GDL: $115.2 \mathrm{MPa}$.

By only changing the thicknesses, there is a variation of $97.9 \%$ between extreme values of von Mises yield criterion at the EP-BPP interface and 95.1\% for the contact pressure at BPP-GDL interface. This observation confirms that thickness plays a key-role in the performance of the FC.

\subsubsection{Most influential constitutive components}

In Table 7 summarizing the factor effects, the EP factor (called D in the DoE) has the highest numerical values. So the EP thickness has a greater influence on stress and contact pressure. The EP thickness controls the behaviour of stress and pressure in the other components. A thin EP considerably dramatically increases the CPress and especially the stress as shown in Table 7. 
Table 7: Total effects of the DoE study with hyperelastic GDL

\begin{tabular}{|c|c|c|c|}
\hline \multirow{4}{*}{ MEA } & A1 & $\begin{array}{c}\text { Total effect on von Mises } \\
\text { yield criterion [MPa] }\end{array}$ & $\begin{array}{c}\text { Total effect on contact pressure } \\
{[\mathrm{MPa}]}\end{array}$ \\
\cline { 2 - 4 } & A2 & $-28,74$ & $-21,96$ \\
\cline { 2 - 4 } & A3 & 16,63 & $-3,96$ \\
\hline \multirow{4}{*}{ GDL } & B1 & 18,18 & 38,88 \\
\cline { 2 - 4 } & B2 & 14,93 & $-9,42$ \\
\cline { 2 - 4 } & B3 & $-4,38$ & 16,12 \\
\hline \multirow{4}{*}{ BPP } & C1 & $-15,82$ & $-10,04$ \\
\cline { 2 - 4 } & C2 & $-2,64$ & 18,12 \\
\cline { 2 - 4 } & C3 & 37,16 & 11,43 \\
\hline \multirow{5}{*}{ EP } & D1 & $-22,13$ & $-25,74$ \\
\cline { 2 - 5 } & D2 & $-39,51$ & $-40,27$ \\
\cline { 2 - 5 } & D3 & $-29,74$ & $-27,45$ \\
\hline
\end{tabular}

It is certain that the EP is an important element to obtain a maximum contact pressure. The smaller thickness of the EP $(7.5 \mathrm{~mm})$ considerably increases the contact pressure and especially the stress. For EP thickness of $30 \mathrm{~mm}$, there is an effect of $54.29 \mathrm{MPa}$ on the contact pressure and 56.08 MPa on von Mises yield criterion.

To find the best EP thickness, it is therefore necessary to choose an EP thickness that can increase the contact pressure without overstraining the EP and the BPP. It will certainly be necessary to look for the best trade-off in the interval [7.5mm; $15 \mathrm{~mm}]$.

\subsection{Effect of the GDL constitutive law}

The comparison between the linear and hyperelastic constitutive laws is presented in Table 8 . For the linear constitutive law, there are high reductions or little rises of the stresses and pressures, comparatively to the tests done with hyperelastic constitutive law. This is due to the different evolutions of the constitutive law in linear and hyperelastic modes. 
Table 8: Difference for maximal pressure and maximal von Mises yield criterion between the hyperelastic and linear laws

\begin{tabular}{|c|c|c|c|c|c|c|}
\hline \multicolumn{7}{|c|}{ Difference between hyperelastic and linear laws } \\
\hline Results & \multicolumn{2}{|c|}{ von Mises yield criterion [MPa] } & \multicolumn{3}{c|}{ Contact pressure [MPa] } \\
\hline & $\begin{array}{c}\text { Contact } \\
\text { GDL-MEA }\end{array}$ & $\begin{array}{c}\text { Contact BPP- } \\
\text { GDL }\end{array}$ & $\begin{array}{c}\text { Contact EP- } \\
\text { BPP }\end{array}$ & $\begin{array}{c}\text { Contact GDL- } \\
\text { MEA }\end{array}$ & $\begin{array}{c}\text { Contact BPP- } \\
\text { GDL }\end{array}$ & $\begin{array}{c}\text { Contact EP- } \\
\text { BPP }\end{array}$ \\
\hline R1 & 2.17 & -4.79 & -1.74 & 2.32 & -2.94 & 2.39 \\
\hline R2 & 2.53 & -3.67 & -5.85 & 3.50 & -1.26 & 2.57 \\
\hline R3 & 3.67 & -2.14 & 0.65 & 5.74 & 0.21 & -0.415 \\
\hline R4 & 5.39 & 10.83 & -0.84 & 6.35 & 23.17 & 0.46 \\
\hline R5 & 9.31 & -4.89 & -2.18 & 2.76 & -4.16 & 4.09 \\
\hline R6 & 3.19 & -6.92 & 3.23 & 3.97 & -4.65 & 3.61 \\
\hline R7 & 4.21 & 4.02 & 0.08 & 2.05 & -9.06 & 0.13 \\
\hline R8 & 10.73 & 21.15 & 4.6 & 15.33 & 52.6 & 4.35 \\
\hline
\end{tabular}

Surprisingly, the change in the GDL constitutive law is not directly related to its thickness. It appears that the influence of thickness ratios between them are predominant for the stress. It seems that the contact pressure is influenced by the thickness of the EP. When it is small or equal to 15, there is a decrease at the GDL-MEA and EP-BPP interfaces, and an increase at the BPP-GDL interface, in comparison with the results of the hyperelastic behaviour law. When the thickness of the EP is $7.5 \mathrm{~mm}$, another distribution can be observed.

The GDL constitutive law does not influence the characteristics of the best thicknesses which optimize the FC performance. On the contrary, the constitutive law affects the extremum of the DoE according to the thickness ratio. This confirms that the GDL constitutive law plays a role in the FC performance. Nevertheless, it seems to have less impact than the variation in thickness.

\subsection{Behaviour of compression and stress at interfaces}

In order to understand the performance, the contact between the interfaces is studied with the von Mises yield criterion. The behaviour of CPress and stress changes according to the thickness ratios and the GDL constitutive law for a given interface. 


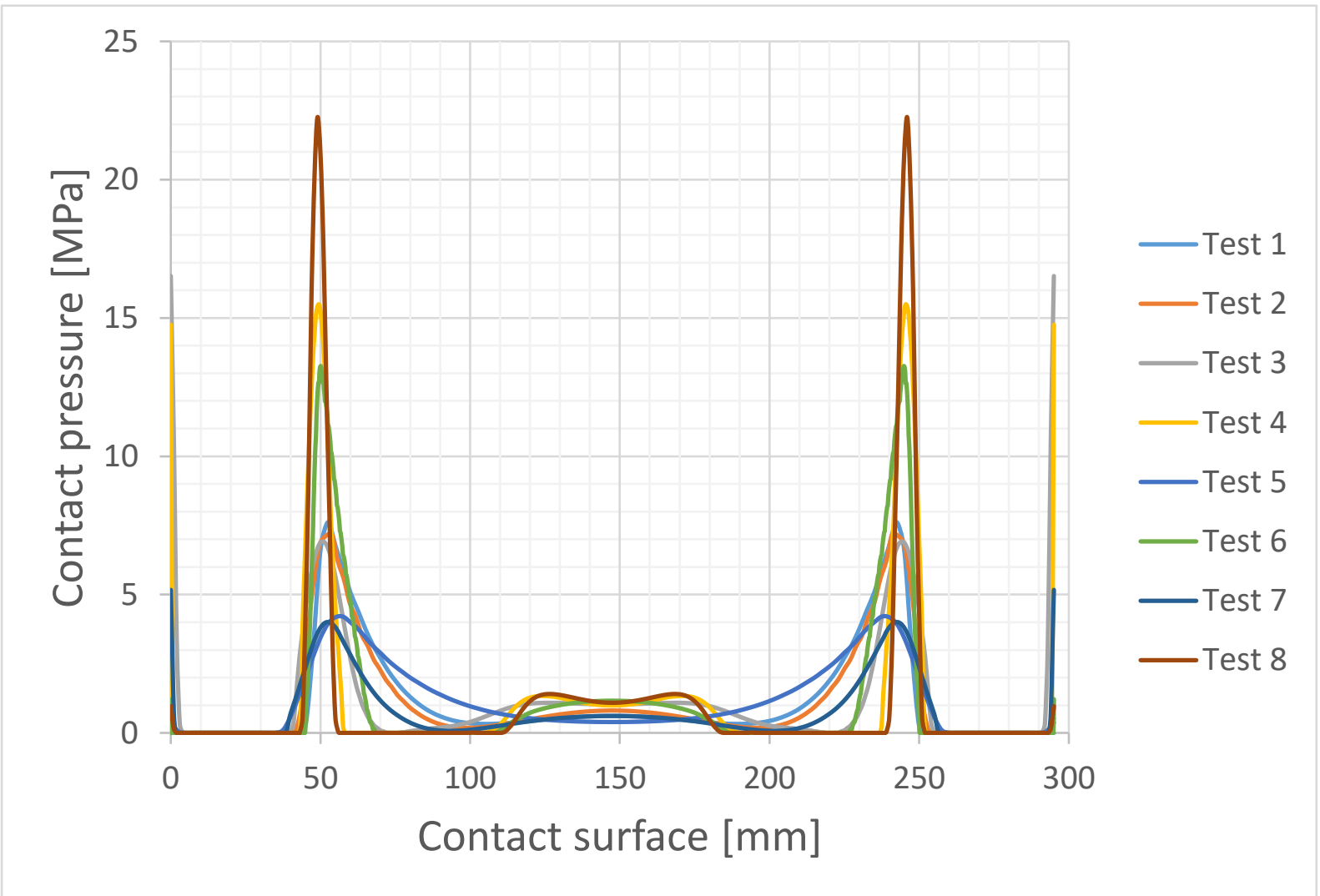

Figure 5: CPress at the EP-BPP interface with hyperelastic GDL

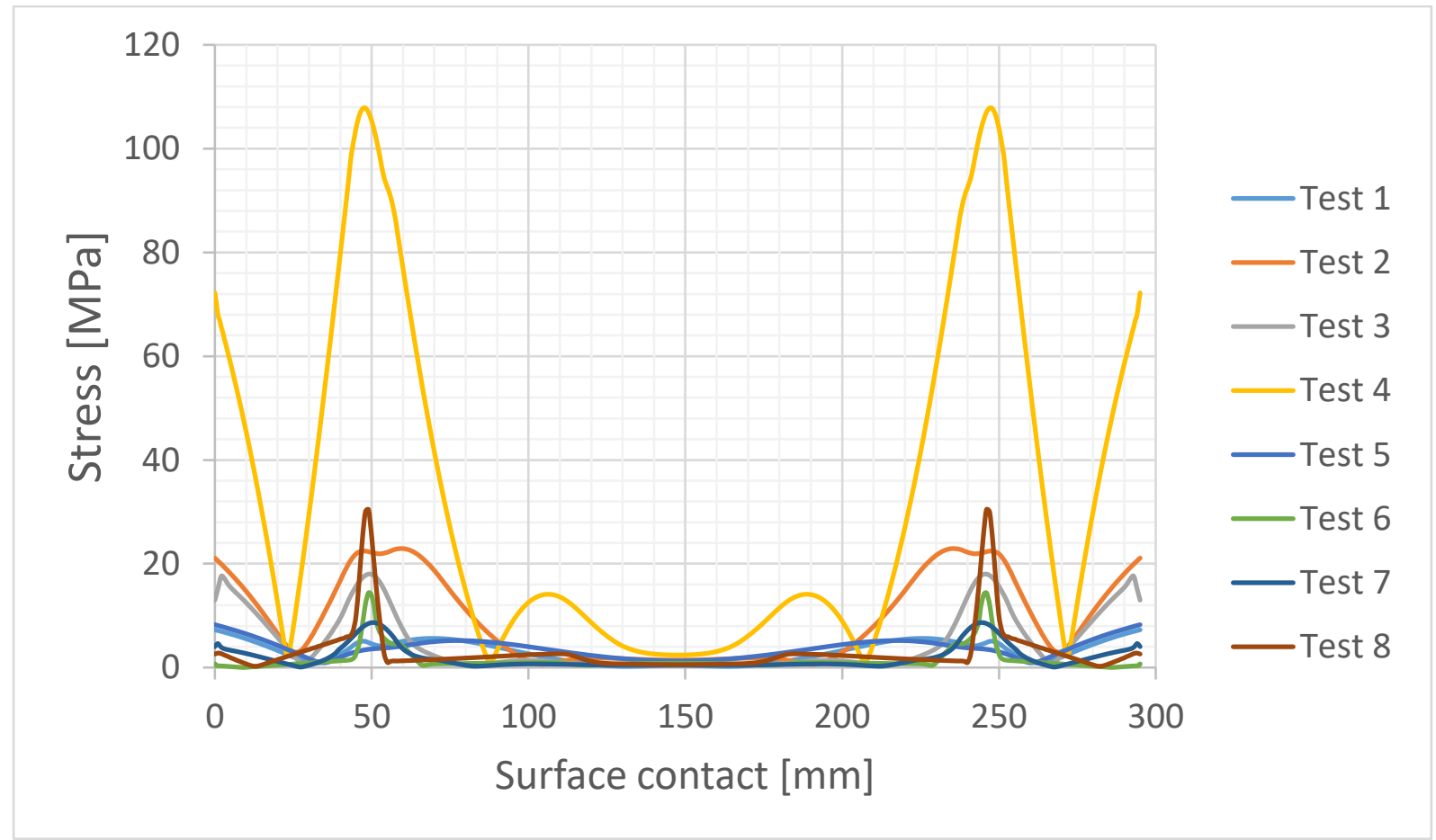

Figure 6: Von Mises yield criterion at the EP-BPP interface with hyperelastic GDL 
For the EP-BPP interface, the simulations led to inhomogeneous but symmetrical behaviours along the surface, as shown in Figures 5 and 6. There is a pressure drop on the edge and in the middle of the interface. A pressure drop means a bad contact between the two interfaces, leading therefore to a debonding. This bad contact can cause an increase in the electric contact resistance inside the fuel cell and therefore induce a loss of performance. As presented in Figure 5 , the pressures vary between 5 and $22 \mathrm{MPa}$ as a function of the thickness ratios.

Overall, for the tests with low pressures under $13.5 \mathrm{MPa}$, there is a correlation between pressure and stress as presented in Figures 5 and 6. When the pressures are low, so are stresses. This is the case for Tests 1, 6, and 7. Others, such as Tests 2, 3 and 6, have medium pressures, and the stresses extend from the maximum pressure area to the centre of the interface. This can sometimes be noticed for a surface contact of $40 \mathrm{~mm}$, as it is the case for Test 2. This suggests that there is slippage and shear between the EP and BPP interfaces.

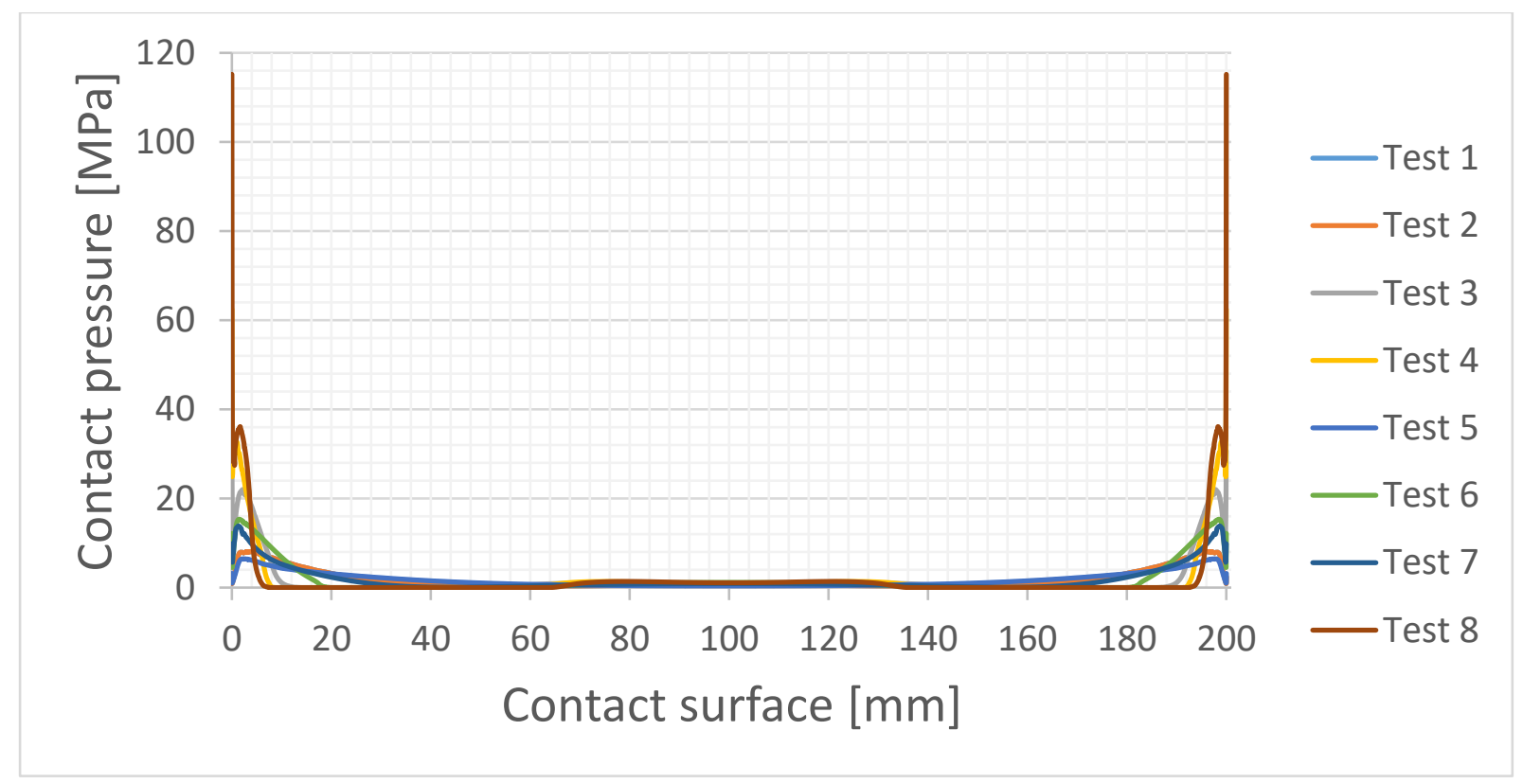

Figure 7: CPress at the BPP-GDL interface with hyperelastic GDL 


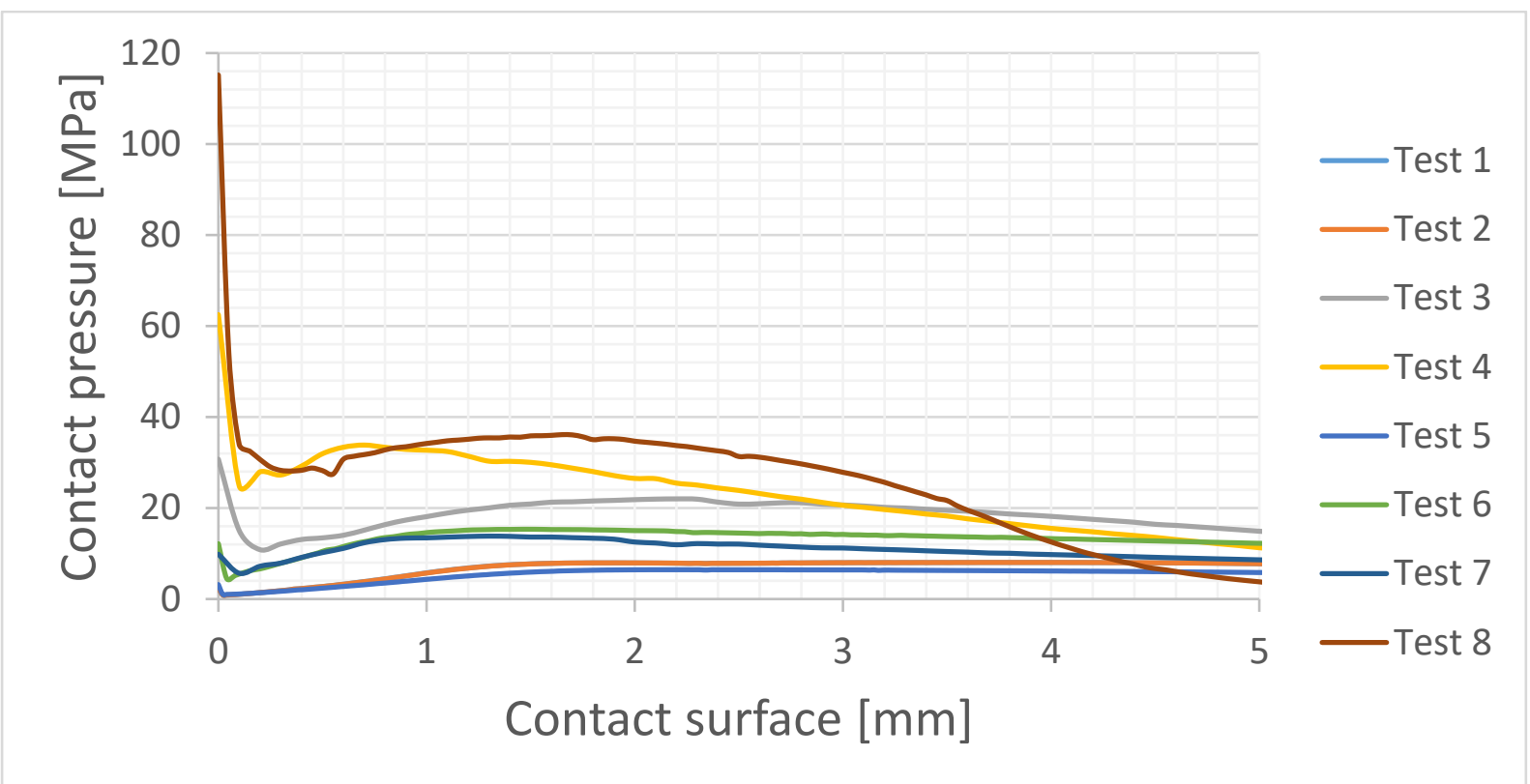

Figure 8: Zoom-in for CPress at the BPP-GDL interface with hyperelastic GDL

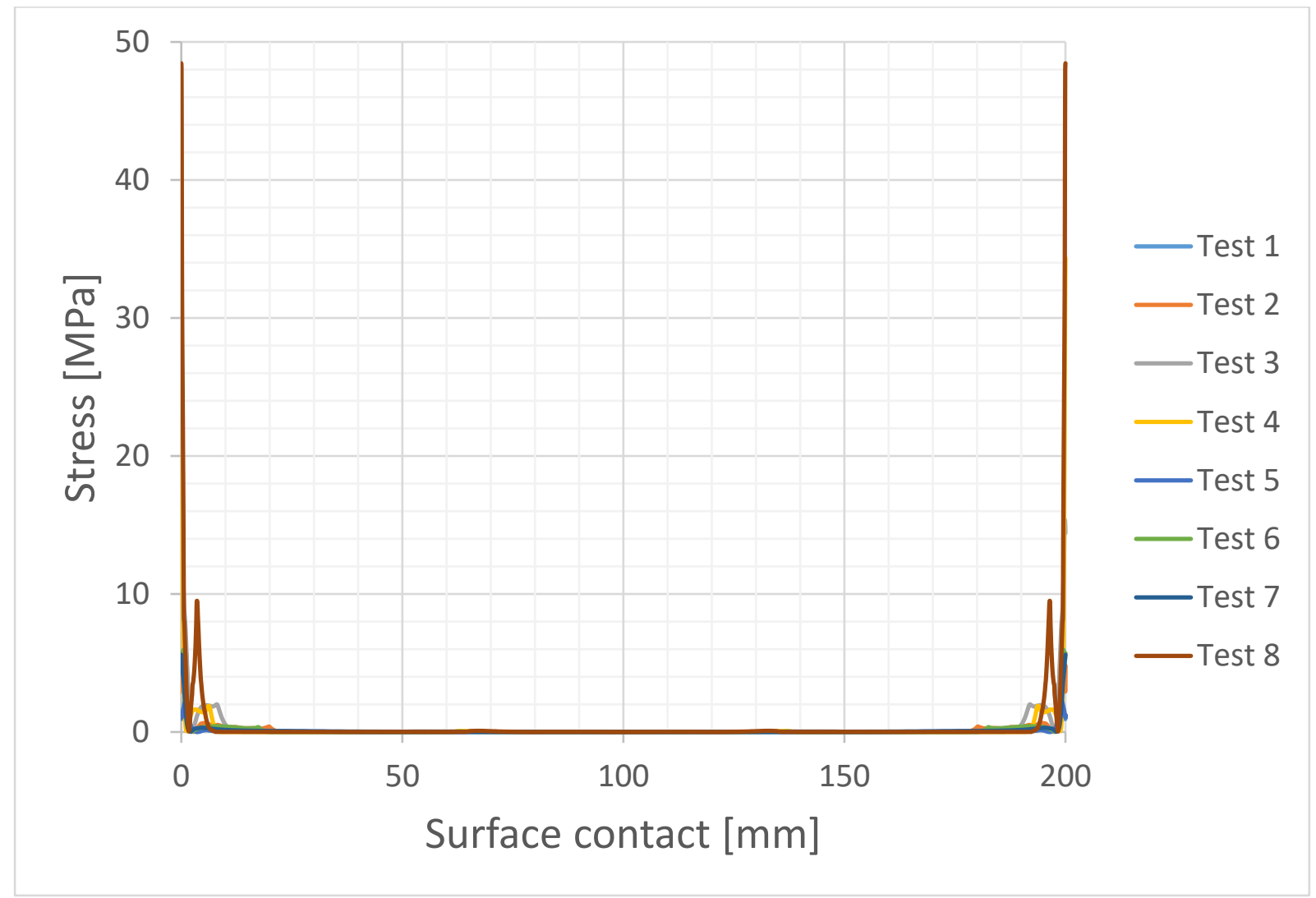

Figure 9: Von Mises yield criterion at the BPP-GDL interface with hyperelastic GDL 


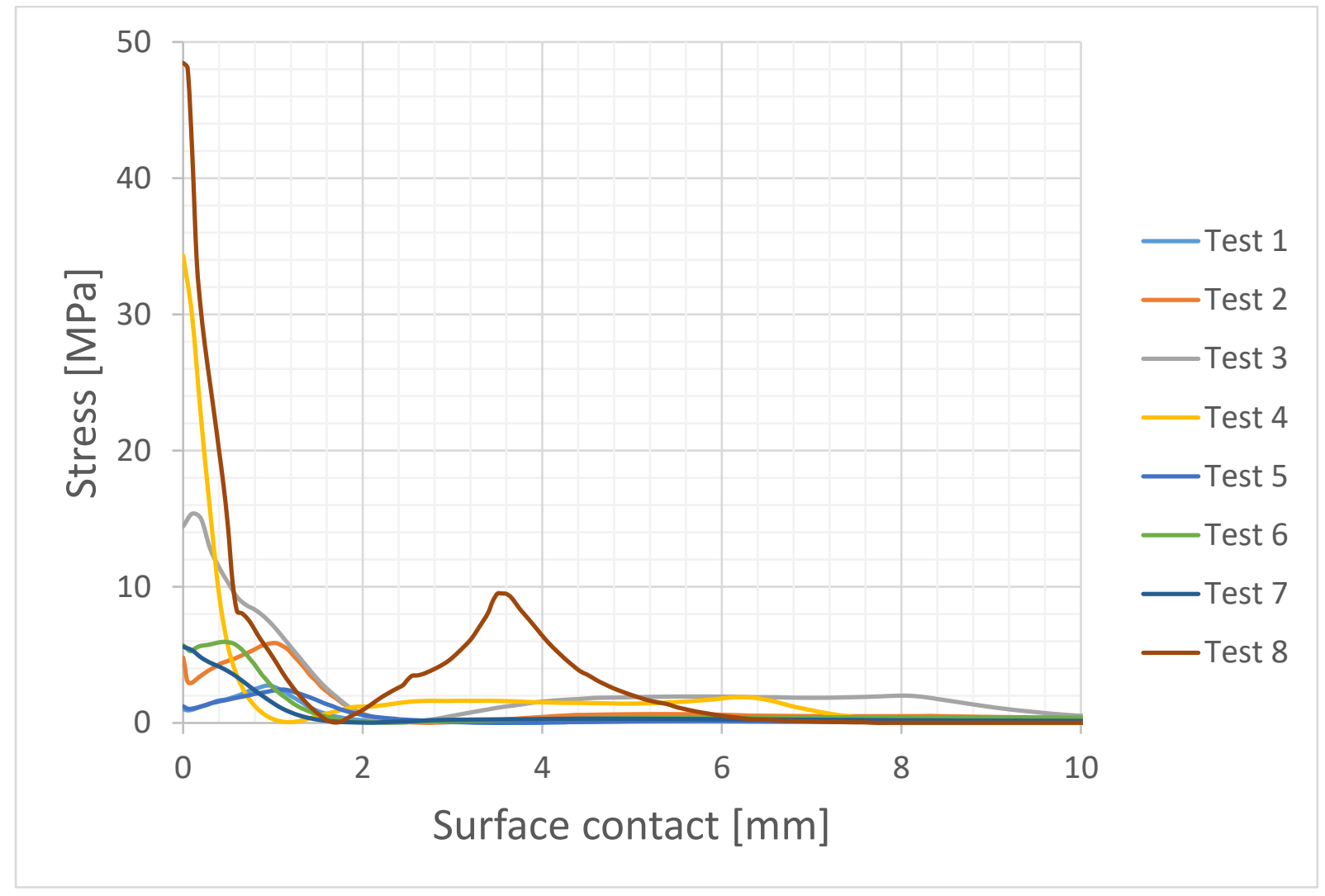

Figure 10: Zoom-in Von Mises yield criterion stress at the BPP-GDL interface with hyperelastic $G D L$

At the BPP-GDL interface, the pressures have their highest values at the edge of the interface. But in the middle of the edge, the mechanical pressures are close to 0. Overall, these pressures range from 0 to $118 \mathrm{MPa}$. It is two times more than the maximum stress of the BPP-GDL interface. The behaviours in pressure and stress at this interface are similar, except at the ends. Further analysis of the tests shows that for each test the highest value of pressure and stress is at the edges of interface, as depicted in Figures 7, 8, 9 and 10. In the range $[0 ; 5 \mathrm{~mm}]$, the contact pressure is greater than the stress. After $5 \mathrm{~mm}$, the values are near to 0 . The contact pressure behaves in a similar way for all the tests: with an overpressure at the edges, then with a depression close to the edge, and a new overpressure until approaching 0 after $5 \mathrm{~mm}$ as in Figure 7. The behaviour of the stresses is much more fluctuating between the different tests, with the same overstress and under-stress pattern as the contact pressures, except for Test 7 given in Figure 9. For example, in Figure 9 and for Test 7, there is no more under stressing close to the edge and for Test 9 , there is considerable overstressing close to $4 \mathrm{~mm}$. There is therefore a real interest in choosing thickness ratios that maximize contact pressures and minimize stress, in order to reduce electronic losses as much as possible and to avoid any mechanical rupture in the PEMFC. 


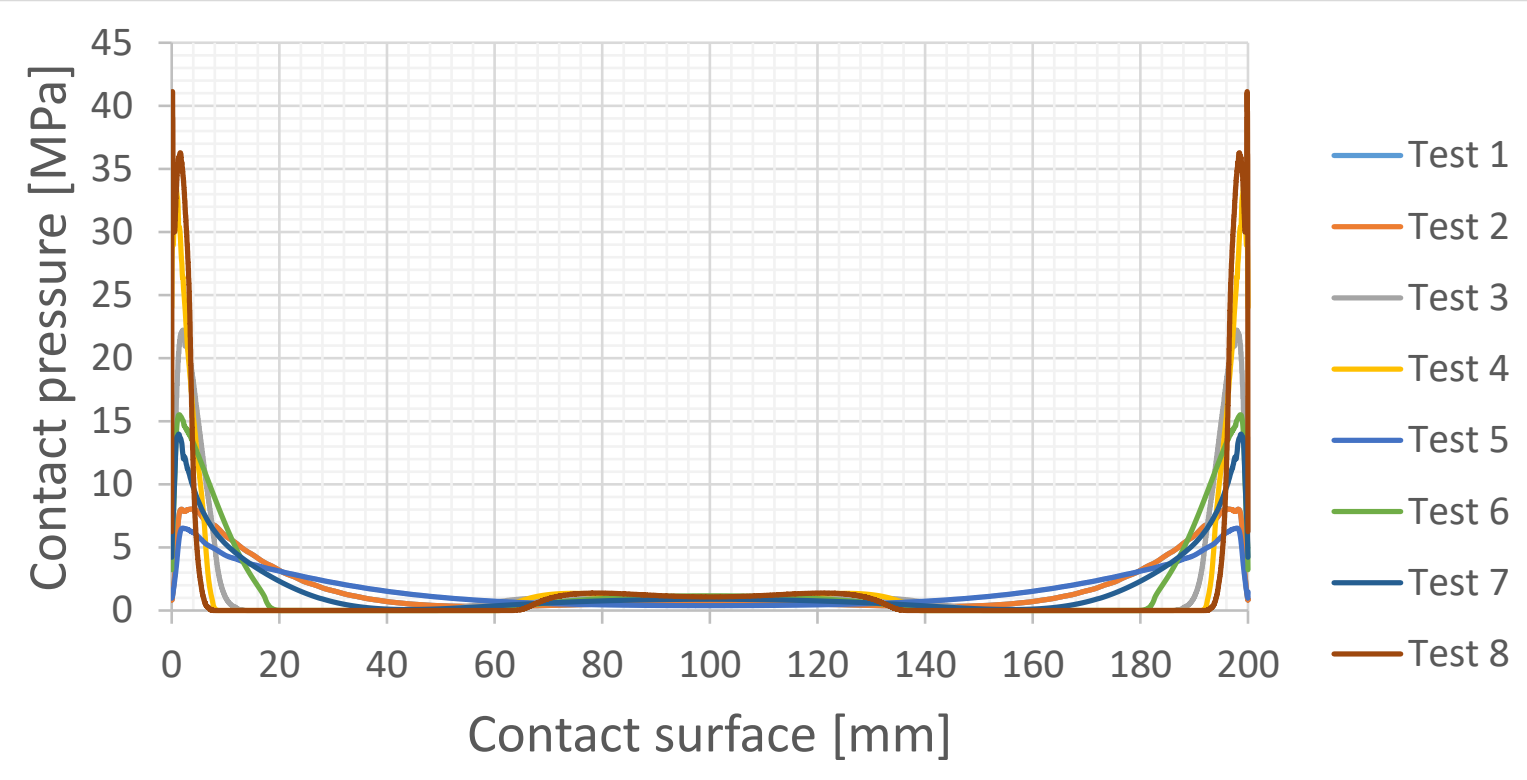

Figure 11: CPress at the GDL-MEA interface with hyperelastic GDL

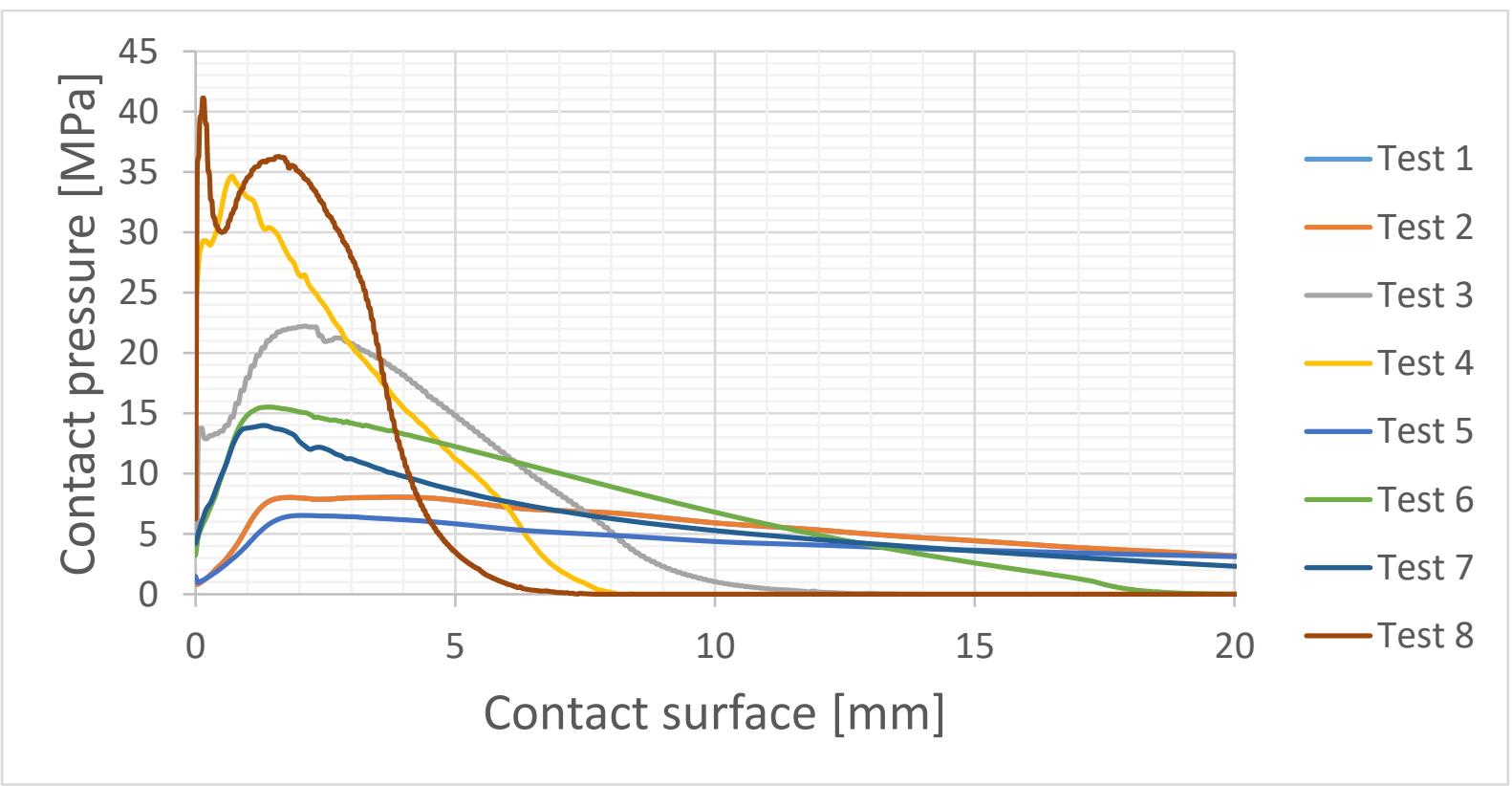

Figure 12: Zoom-in for CPress at the GDL-MEA interface with hyperelastic GDL 


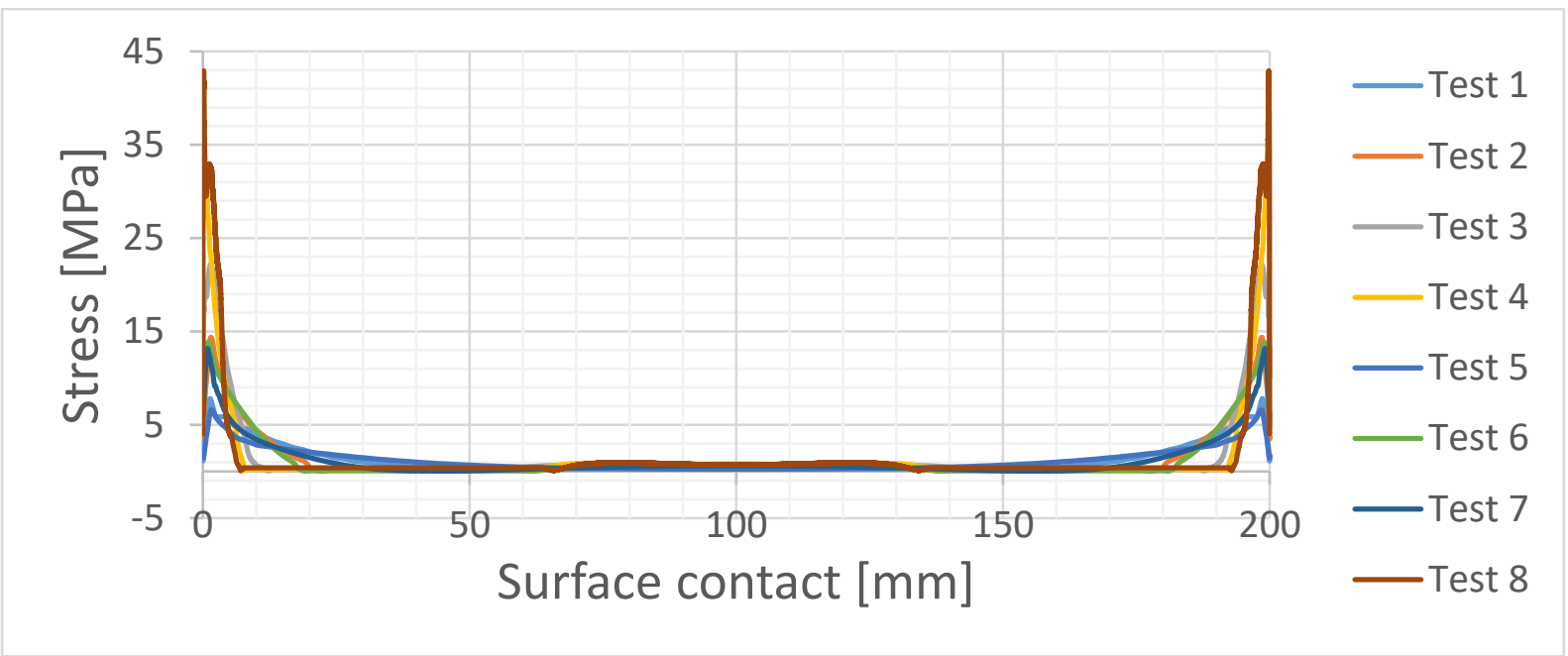

Figure 13: Von Mises yield criterion at the GDL-MEA interface with hyperelastic GDL

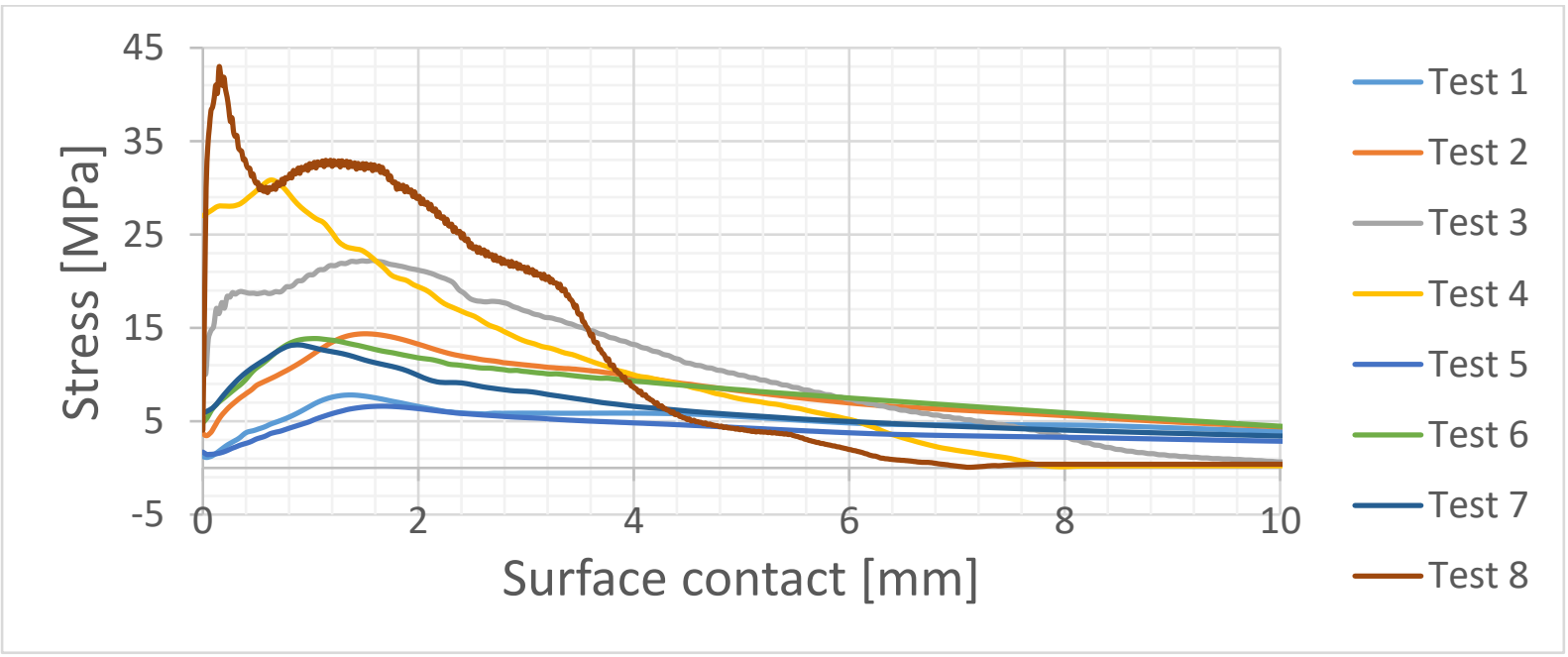

Figure 14: Zoom-in for von Mises yield criterion stress at the GDL-MEA interface with hyperelastic GDL

Figures 11, 12, 13 and 14 shows that the GDL-MEA interface has the same behaviour than the BPP-GDL interface. The pressures are at their highest at the ends and drop sharply to $0 \mathrm{MPa}$. Therefore, we have a pressure concentration at the ends and then a bonding and a debonding in the middle of the structure. This creates a high variation in resistance throughout the structure. A closer examination at the ends shows that, for this interface, the behaviour of the stresses is identical to the pressures. When the pressure is at its highest, the stresses are at their highest. Even when it is minimal, so are the stresses. This observation is similar for each test. 


\subsection{Best set of parameters}

According to our effect analysis table, the best EP thickness seems to be in the [7.5mm; $15 \mathrm{~mm}]$ interval. We chose the thickness of $15 \mathrm{~mm}$ (D2) with the least negative influence on the contact stress and pressure as presented in Table 5. The best compromise for the MEA is the thickness of $0.05 \mathrm{~mm}$ (A1) in Table 4. The contribution of the thickness of the MEA to the performance of the FC is quite significant after the EP. As far as GDL is concerned, it is certain that the best choice is that of $\mathrm{B} 2$ and therefore the thickness $0.28 \mathrm{~mm}$ which will reduce the stress by maximizing the contact pressure. Finally, for the BPP, the best parameter according to Table 7 is $\mathrm{C} 1$ with a thickness equal to $3 \mathrm{~mm}$.

Our most unfavourable case is with the linear behaviour because the lowest value of von Mises yield criterion increases and drastically reduces the greater value of CPress, compared to the tests with the hyperelastic constitutive law. That is why for the model of best sets of parameters, the constitutive law for GDL is hyperelastic.

An optimal simulation is performed with 182189 nodes and 161725 elements. The maximum values of von Mises yield criterion do not exceed the elastic limit that each component can withstand as given in Tables 9 and 10 .

The von Mises yield criterion is significant in contact with the GDL-MEA and EP-BPP interfaces, but it allows to have a high contact pressure.

Table 9: Max von Mises yield criterion and CPress

\begin{tabular}{|c|c|c|}
\hline \multicolumn{3}{|c|}{ Optimal results } \\
\hline Contact type & $\begin{array}{c}\text { Max. von Mises yield } \\
\text { criterion }[\mathrm{MPa}]\end{array}$ & $\begin{array}{c}\text { Max. contact pressure } \\
{[\mathrm{MPa}]}\end{array}$ \\
\hline Contact GDL-MEA & 15 & 16 \\
\hline Contact BPP-GDL & 6 & 16 \\
\hline Contact EP-BPP & 29 & 13 \\
\hline
\end{tabular}

Table 10: Elastic limits of different constitutive materials

\begin{tabular}{|c|c|c|}
\hline Component & Material & Elastic limits (MPa) \\
\hline End Plate (D) & Aluminium alloy & $220[29]$ \\
\hline BPP (C) & Graphite & $50[30]$ \\
\hline GDL (B) & Carbon paper (TGP-H-90) & $40[31]$ \\
\hline MEA (A) & Nafion & $23-32[32]$ \\
\hline
\end{tabular}




\subsection{Effect of the pressure distribution on the electrical contact resistance}

The work of Bouziane et al [33] makes possible to compute the electrical contact resistance between GDL and BPP. The TLM method is used to measure the contact resistance under 5 compression cycles over several mechanical pressure stages ranging from 0 to $8 \mathrm{MPa}$. The most interesting values to compute the contact resistance is obtained for the loading phase applied during the first cycle. We focused on the data linked to the GDL ref. Toray H90 with a 0.28 $\mathrm{mm}$ thickness. From Figure 5, it is possible to obtain the distribution of contact resistances shown in Figure 15 by applying the approach described in [25, 34]. The electrical contact resistance of the BPP-GDL interface is a non-linear function with respect to the thickness of the BPP. The model can also be used to compute the electrical resistance of the BPP-GDL interface: $3.49 \mathrm{~m} \Omega$ for Test 2, $3.09 \mathrm{~m} \Omega$ for Test 5 and $19.9 \mathrm{~m} \Omega$ for Test 8 .

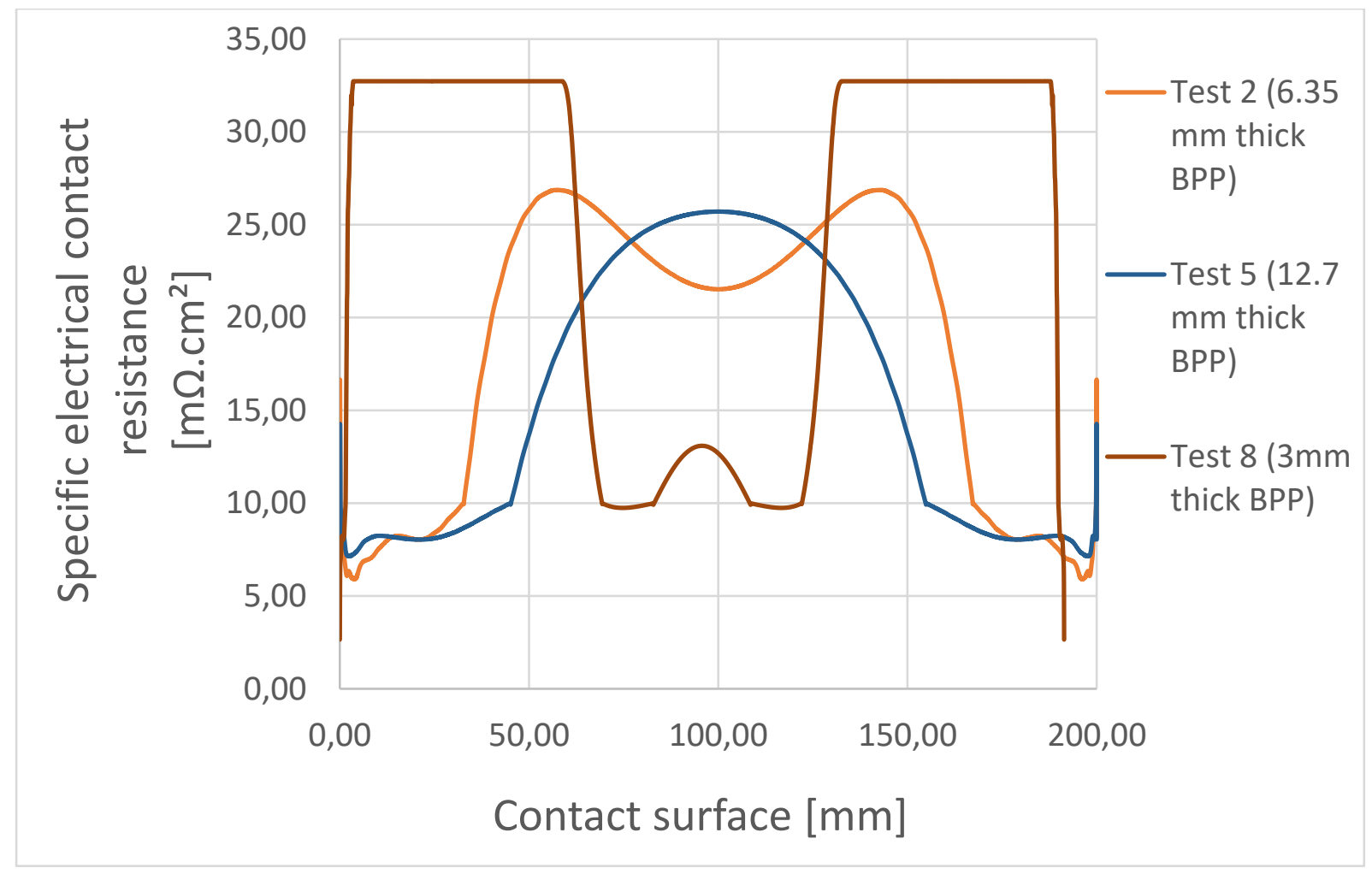

Figure 15: Distribution of the electrical contact resistance at the GLD-BPP interface for the GDL ref. Toray $\mathrm{H} 90$

The comparison between Test 2, Test 5 , and Test 8 shows that increasing the size ratio between the MEA and the BPP spreads the resistance at the edges of the GDL, and also increases the contact resistance on the surface of the GDL. Increasing the size ratio between EP and BPP 
increases the contact resistance, thus decreasing the contact pressure. Adopting thin components increases the contact resistance. Therefore, the most favourable case seems to have thick and equivalent thicknesses between the different components.

\section{Comparison with literature}

To verify the validity of our model, we compare the pressure distributions on GDL and MEA from experiments and numerical models.

Experimentally, there are two major in-situ techniques used to measure contact pressure distributions [8]. The first technique uses pressure sensitive films composed of two polyester based sheets which one of them is coated with a layer of micro-encapsulated colour forming material and the other one is coated with a layer of colour developing material [35]. Pressure is approximated depending on the density of red spots. The second tool for evaluating the pressure distribution is the use of piezoelectric sensors, as in the work of Dey et al. [36].

Most of the works are not usable since the clamping system is with nuts and bolts. The distributed pressure is therefore not uniform. As pointed out in the work of Wen et al. [35], positions of nuts and their number have considerable influence on the pressing process. This is partly due to the buckling of the endplate.

The experimental work of Alizadeh [20] makes possible to validate the stress distribution for the MEA and the pressure distribution on the GDL. The loading conditions are identical to our model. They used pneumatic clamping system which can compress the cell at 7 bars. The contact pressure distribution over the active area of the PEMFC is obtained using super lowpressure Fujifilm used with a range of $[0.5 ; 2.5] \mathrm{MPa}$ inserted between two GDLs as depicted in Figure 16. Their work confirms the behaviour obtained on the MEA and the GDL for both the numerical model and the experimental test. However, the values of pressures and stresses are not similar. This may possibly be explained by the hyperelastic constitutive law used to model the GDL behaviour. 


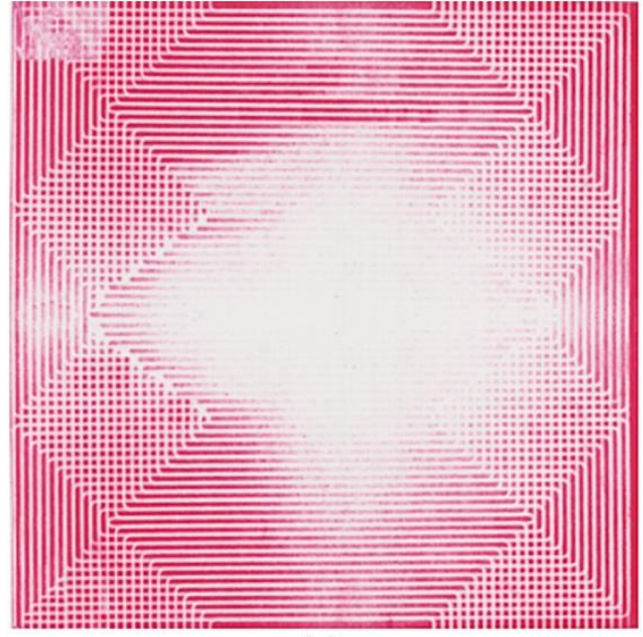

(a)

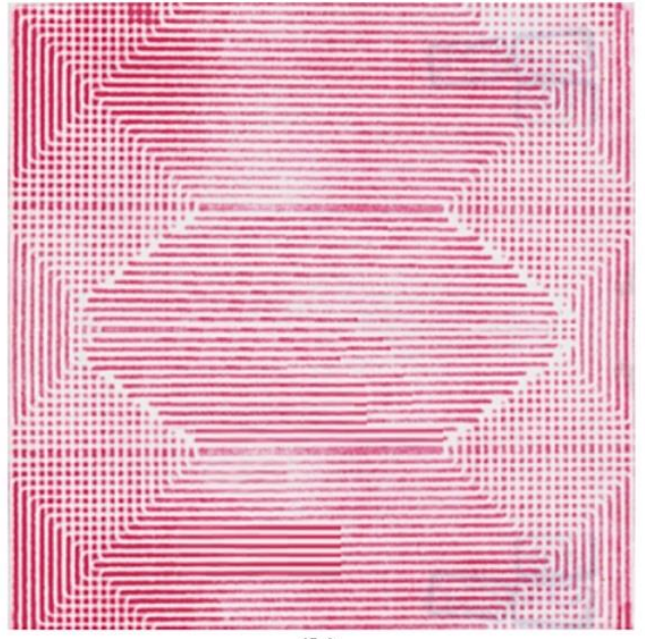

(b)

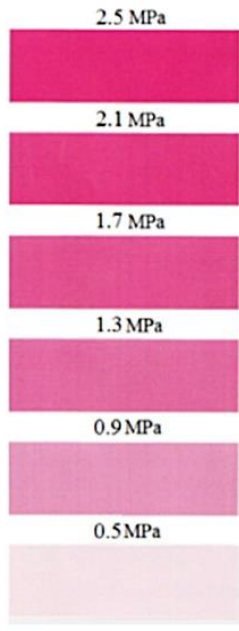

Figure 16: Contact pressure distributions over the MEA of PEM Single cell: (a) Stainless steel end plate with $30 \mathrm{~mm}$ thickness, (b) Stainless steel end plate with $50 \mathrm{~mm}$ thickness [20].

In their work, Bates et al [37] have obtained the same behaviour of the von Mises constraints, although the clamping system does not match our model. In their model, the clamping system consists of nuts and bolts. They have performed two simulations: a single-cell and a 16-cell stack were run under various clamping pressures. In both models, a linear behaviour law is applied to the GDL and to all other elements. Only the single-cell model is used and compared to our test with the closest thicknesses. The same stress distribution is seen on the EP/BPP and GDL/MEA interfaces as shown in Figure 17, but the presence of the BPP channels considerably changes the mechanical behaviour of the BPP/GDL interface.

(a)

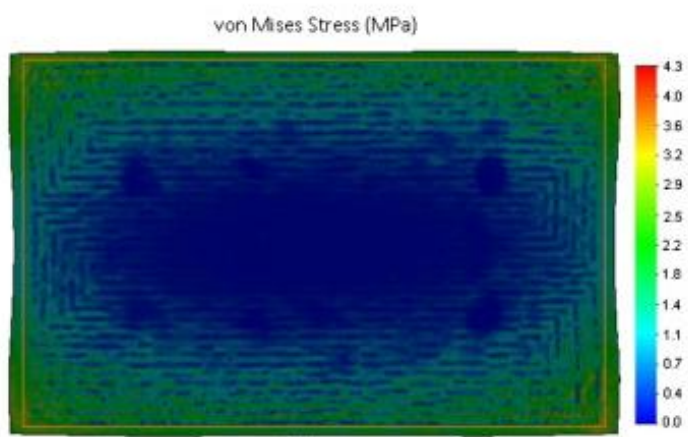

(b)

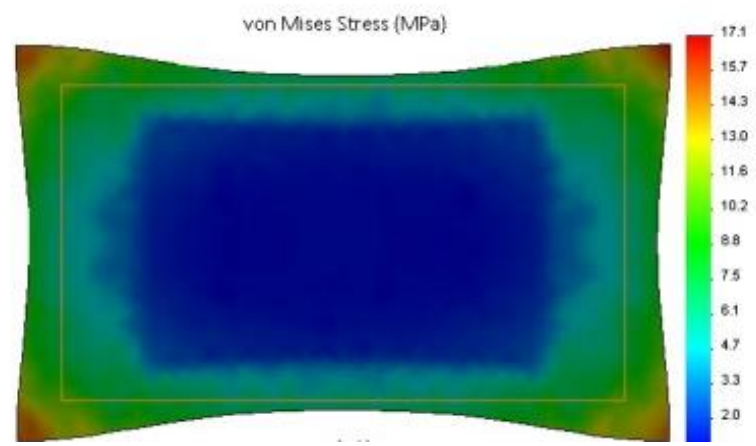

Figure 17: Von Mises stress distribution (single cell, active area $=100 \mathrm{~cm}^{2}$ ): a) deformed GDL stress plot, $(b)$ deformed MEA stress plot [37].

With the Zhang et al.' work [34], a numerical comparison of the pressure distribution obtained at the BPP/GDL interface is possible. They have experimentally obtained a contact resistance- 
pressure constitutive relation for the contact between the BPP and the GDL, and estimated the contact pressure in a real fuel cell stack based on either geometrical relations or FEM analysis. The load corresponding to our model corresponds to a uniform load distribution. The numerical results of the pressure distribution on the BPP/GDL interface are in line with the results obtained in this paper although there are channel print marks.

\section{Conclusions}

The article presents a study of the mechanical behaviour of a PEMFC with a focus on the contact pressure distribution and electrical contact resistance at different layer interfaces in the stack. A numerical development was initiated in order to quantify the influences of thickness of cell components and constitutive law of the GDL on the PEMFC performances expressed in terms of electrical resistances at the early-stage design of a PEMFC. To reach this aim, a 2D finite element model including contact friction was developed and combined with a DoE. Concerning the GDL, a hyperelastic experimental constitutive law and a linear constitutive law were implemented. An optimal set of geometric and mechanical parameters were determined. During the computation process, it appeared that the ratios between the thicknesses of the cell components influence the computation stability. After reviewing the simulation results, we noted that the electrical and mechanical responses are more impacted by the layer thicknesses than by the GDL constitutive law.

\section{Acknowledgements:}

The "Région Bourgogne-Franche-Comté" is gratefully acknowledged for its support through the ELICOP Project (Ref. 2015C-4944 and 2015-4948). The French "Ministère de l'Enseignement supérieur, de la Recherche et de l'Innovation" is gratefully acknowledged for the funding of Khadidja Bouziane's PhD Thesis (Contrat doctoral Univ. Paris Sud n²017-225). 


\section{References}

[1] Luo X, Wang J, Dooner M, Clarke J. Overview of current development in electrical energy storage technologies and the application potential in power system operation. Applied Energy 2015;137:511-36. https://doi.org/10.1016/j.apenergy.2014.09.081.

[2] Kazim A. Introduction of PEM fuel-cell vehicles in the transportation sector of the United Arab Emirates. Applied Energy 2003;74(1-2):125-33. https://doi.org/0.1016/S0306-2619(02)00138-1.

[3] Giacoppo G, Hovland S, Barbera O. 2 kW Modular PEM fuel cell stack for space applications: Development and test for operation under relevant conditions. Applied Energy 2019;242:1683-96 https://doi.org/10.1016/j.apenergy.2019.03.188.

[4] Park J, Oh H, Ha T, Lee YI, Min K. A review of the gas diffusion layer in proton exchange membrane fuel cells: Durability and degradation. Applied Energy 2015;155:866-80. https://doi.org/10.1016/j.apenergy.2015.06.068.

[5] Pei P, Chen H. Main factors affecting the lifetime of Proton Exchange Membrane fuel cells in vehicle applications: A review. Applied Energy 2014;125:60-75. https://doi.org/10.1016/j.apenergy.2014.03.048.

[6] Zhang H, Li X, Liu X, Yan J. Enhancing fuel cell durability for fuel cell plug-in hybrid electric vehicles through strategic power management. Applied Energy 2019;241:483-90. https://doi.org/10.1016/j.apenergy.2019.02.040.

[7] Hou Y., Zhang X., Lu X., Hao D., Ma L., Li P., AC impedance characteristics of a vehicle PEM fuel cell stack under strengthened road vibrating, Int. J. Hydrog. Energy 2014;39:32:18362-18368. https://doi.org/10.1016/j.ijhydene.2014.09.054.

[8] Khetabi E.M., Bouziane K., Zamel N., François X., Meyer Y., Candusso D., Effects of mechanical compression on the performance of polymer electrolyte fuel cells and analysis through in-situ characterisation techniques - A review, J. Power Sources 2019;424:8-26. https://doi.org/10.1016/j.jpowsour.2019.03.071.

[9] Saadat, N., Dhakal, H. N., Tjong, J., Jaffer, S., Yang, W., Sain, M. Recent advances and future perspectives of carbon materials for fuel cell. Renewable and Sustainable Energy Reviews 2021; 110535. https://doi.org/10.1016/j.rser.2020.110535

[10] Diampovesa, S., Hubert, A., Yvars, P. A., Meyer, Y., Zimmer, L. (2019). Optimal design for electromagnetic devices: A synthesis approach using intervals and constraint-based methods. International Journal of Applied Electromagnetics and Mechanics 2019; 60(S1), S35-S48. https://doi.org/10.3233/JAE-191104

[11] Alizadeh E., Ghadimi M., Berzagui M., Momenifar M., Saadat S., Development of contact pressure distribution of PEM fuel cell's MEA using novel clamping mechanism, Energy 2017;131:92-97. https://doi.org/10.1016/j.energy.2017.05.036

[12] Wang X., Song Y., Zhang B., Experimental study on clamping pressure distribution in PEM fuel cells, J. Power Sources 2008;179:305-309. https://doi.org/10.1016/j.jpowsour.2007.12.055

[13] Hou Y., Zhou B., Zhou W., Shen C., He Y., An investigation of characteristic parameter variations of the polarization curve of a proton exchange membrane fuel cell stack under strengthened road vibrating conditions, Int. J. Hydro. Energy 2012;37:11887-11893. https://doi.org/10.1016/j.ijhydene.2012.05.030 
[14] Zhou Y., Jiao K., Du Q., Yin Y., Li X., Gas diffusion layer deformation and its effect on the transport characteristics and performance of proton exchange membrane fuel cell., Int. J. Hydrog. Energy 2013;39:12891-12903. https://doi.org/10.1016/j.ijhydene.2013.05.150

[15] García-Salaberri, P. A., Vera, M., \& Zaera, R. (2011). Nonlinear orthotropic model of the inhomogeneous assembly compression of PEM fuel cell gas diffusion layers. International Journal of Hydrogen Energy, 36(18), 11856-11870. https://doi.org/10.1016/i.ijhydene.2011.05.152

[16] Zhang, Z., He, P., Dai, Y. J., Jin, P. H., \& Tao, W. Q. (2020). Study of the mechanical behavior of paper-type GDL in PEMFC based on microstructure morphology. International Journal of Hydrogen Energy, 45(53), 29379-29394. https://doi.org/10.1016/i.ijhydene.2020.07.240

[17] Netwall CJ, Gould BD, Rodgers JA, Nasello NJ, Swider-Lyons KE. Decreasing contact resistance in proton-exchange membrane fuel cells with metal bipolar plates. J. Power Sources 2013;227:137-44. https://doi.org/10.1016/j.jpowsour.2012.11.012.

[18] Ye D, Gauthier E, Benziger JB, Pan M. Bulk and contact resistances of gas diffusion layers in proton exchange membrane fuel cells. J. Power Sources 2014;256:449-56. https://doi.org/10.1016/j.jpowsour.2014.01.082.

[19] Zhou P., Wu C.W., Ma G.J. Contact resistance prediction and structure optimization of bipolar plates. J. Power Sources 2006;159:2:1115-1122.https://doi.org/10.1016/j.jpowsour.2005.12.080

[20] Alizadeh A., Barzegari M., Momenifar M., Ghadimi M., Saadat S., Investigation of contact pressure distribution over the active area of PEM fuel cell stack. Int. J. Hydrog. Energy 2016;41:3062-3071. https://doi.org/10.1016/j.ijhydene.2015.12.057

[21] Atyabi, S. A., Afshari, E., Wongwises, S., Yan, W. M., Hadjadj, A., Shadloo, M. S. Effects of assembly pressure on PEM fuel cell performance by taking into accounts electrical and thermal contact resistances. Energy 2019;179,490-501. https://doi.org/10.1016/j.energy.2019.05.031

[22] Lai, X., Peng, L., Ni, J. A mechanical-electrical finite element method model for predicting contact resistance between bipolar plate and gas diffusion layer in PEM fuel cells. Journal of Power Sources 2008;182(1),153-159. https://doi.org/10.1016/j.jpowsour.2008.03.069

[23] (ABAQUS 2018) ABAQUS/Standard User's Manual, Version 6.13. Providence, RI: Dassault Systèmes Simulia Corp, 2018. [accessed 27 April 2020]

[24] Carral C, Mele P. A numerical analysis of PEMFC stack assembly through a 3D finite element model. Int J Hydrog Energy 2014;39:9:4516-4530. https://doi.org/10.1016/j.ijhydene.2014.01.036

[25] Mishra, V., Yang, F., Pitchumani, R., Measurement and prediction of electrical contact resistance between gas diffusion layers and bipolar plate for applications to pem fuel cells, J. Fuel Cell Sci. Technol. 2004;1:1:2-9. https://doi.org/10.1115/1.1782917

[26] Gigos P.A., Faydi Y., Meyer Y., Mechanical characterization and analytical modeling of gas diffusion layers under cyclic compression, Int. J. Hydrog. Energy 2015;40:17:5958-5965. https://doi.org/10.1016/j.ijhydene.2015.02.136

[27] Choi, P., Jalani, N. H., Thampan, T. M., Datta, R. Consideration of thermodynamic, transport, and mechanical properties in the design of polymer electrolyte membranes for higher temperature fuel cell operation. J. Polym. Sci. B Polym. Phys. 2006;44:16:2183-2200. https://doi.org/10.1002/polb.20858

[28] Joneja A., Design Principles, The Hong Kong University of Science and Technology, 2001. 
[29] http://www.almet-metal.com/informations-techniques/donnees-aluminium [accessed 27 April 2020]

[30] https://www.sceram.com/graphite/ [accessed 27 April 2020]

[31] https://www.fuelcellstore.com/toray-carbon-paper-060 [accessed 27 April 2020]

[32] https://www.fuelcellstore.com/spec-sheets/chemours-nafion-211-212-spec-sheet.pdf [accessed 27 April 2020]

[33] Bouziane, K., Lachat, R., Zamel, N., Meyer, Y., \& Candusso, D. Impact of cyclic mechanical compression on the electrical contact resistance between the gas diffusion layer and the bipolar plate of a polymer electrolyte membrane fuel cell. Renewable Energy 2020;153:349-361. https://doi.org/10.1016/j.renene.2020.02.033

[34] Zhang L., Liu Y., Song H., Wang S., Zhou Y., Hu S. J., Estimation of contact resistance in proton exchange membrane fuel cells. J. Power Sources 2006;1162:2:1165-1171. https://doi.org/10.1016/j.jpowsour.2006.07.070

[35] Wen C.-Y., Lin Y.-S., Lu C.-H. Experimental study of clamping effects on the performances of a single proton exchange membrane fuel cell and a 10-cell stack. J. Power Sources 2009;192:2:475485. https://doi.org/10.1016/j.jpowsour.2009.03.058

[36] Dey, T., Deshpande, J., Singdeo, D., Ghosh, P. C. Study of PEM fuel cell end plate design by structural analysis based on contact pressure. Journal of Energy 2019; 11 pages. Article ID 3821082. https://doi.org/10.1155/2019/3821082

[37] Bates A., Mukherjee S., Hwang S., Lee S. C., Kwon O., Choi G. H., Park S. Simulation and experimental analysis of the clamping pressure distribution in a PEM fuel cell. Int. J. Hydrogen Energy 2013;38:15:6481-6493. https://doi.org/10.1016/j.ijhydene.2013.03.049 